VISUALS DOMINATE INVESTOR JUDGMENT

VISUALS DOMINATE INVESTOR DECISIONS

ABOUT ENTREPRENEURIAL PITCHES

\author{
CHIA-JUNG TSAY \\ UCL School of Management \\ University College London \\ 1 Canada Square \\ London E14 5AB UK \\ e-mail : c.tsay@ucl.ac.uk
}


VISUALS DOMINATE INVESTOR JUDGMENT

\title{
Visuals Dominate Investor Decisions about Entrepreneurial Pitches
}

\begin{abstract}
Entrepreneurs and investors often deem substantive content to be particularly important as they evaluate the potential value of business propositions. Yet across 12 studies and 1,855 participants using live entrepreneurial pitch competitions, silent videos_-but not sound recordings, video-with-sound recordings, or pitch transcriptions - best allowed both experts and novices to identify the original investors' selections of winning entrepreneurial pitches. These results suggest that people's judgment may be highly influenced by visual information. Further, people do not seem to fully recognize how much visual information factors into their decisions, such that they neglect the more substantive metrics that they explicitly cite and value as core to their decisions. The findings highlight the power of dynamic visual cues - including gestures, facial expressions, and body language - and demonstrate that visible passion can dominate the content of business propositions in entrepreneurial pitch competitions.
\end{abstract}

Key words: social perception; cognition; judgment and decision making; evaluation; performance; entrepreneurship; visual cues 


\section{VISUALS DOMINATE INVESTOR JUDGMENT}

There were over 30.7 million small businesses in the United States alone in 2019 (U.S. Small Business Administration, 2019), and 77\% of American entrepreneurs rely on their personal savings for their initial funding (Gallup, 2014). The need for more sustainable sources of funding points to the critical role of pitch competitions. Winners of such competitions gain access to seed funding that can vary from several thousand dollars to over $\$ 1$ million, as in the Hult Prize Accelerator or the Startup World Cup. In addition to funding (Robbie \& Mike 1998), winners secure exposure, mentorship opportunities, incubator space, access to networks, and other forms of support (Zott \& Huy 2007). Clearly, pitches are critical moments for entrepreneurs that impact the viability and success of their ventures (Hellman \& Puri, 2000; Kaplan \& Stromberg, 2003; Shane, 2000). However, investors often make decisions about pitches before objective performance measures or actual outputs are available for evaluation (Elsbach \& Kramer, 2003; Stevens \& Kristoff, 1995). Not surprisingly, then, even experienced investors often perform below chance when betting on ventures (Wiltbank et al., 2009; Zacharakis \& Meyer, 2000).

Experts are often tapped to evaluate the more objective aspects of entrepreneurs' pitches, such as business models, competitive advantages, and financial expectations (Chen et al., 2009; Kelley, 2001; Rasmussen \& Sorheim, 2012). For example, angel investors consciously attribute their investment-related decisions to substance-oriented, non-presentational criteria, such as information about the company, the market, the product, and funding or finance issues (Clark, 2008). Some research has suggested that venture or project characteristics may be weighted above characteristics of the entrepreneurs (Chen et al., 2009; Clark, 2008; Mitteness et al., 2012; Petty \& Gruber, 2011). Decision makers value information about an entrepreneur's business proposition (Amit et al., 1990; Fried \& Hisrich, 1994), which can include the venture's market (Hall \& Hofer, 


\section{VISUALS DOMINATE INVESTOR JUDGMENT}

1993; Shepherd, 1999), competition (Zacharakis \& Meyer, 2000), strategies (Martens et al., 2007; Tyebjee \& Bruno, 1984), resources (Shepherd, 1999), finances (Hall \& Hofer, 1993; Muzyka \& Birley, 1996), and industry characteristics (Martens et al., 2007). In addition, experts may be aware that access to certain types of non-diagnostic information can have adverse consequences (Dovidio et al., 1986; Gaertner \& McLaughlin, 1983; Gilbert \& Hixon, 1991; Sager \& Schofield, 1980; Smith, 1984; Smith \& Branscombe, 1985).

Yet judgment of pitches may incorporate information that is less related to the quality of a business proposition, such as body movement and other nonverbal behaviors (Baron \& Brush, 1999; Ko et al., 2009; Pentland, 2010). After all, people may discount evidence about actual competence in favor of the appearance of competence (Anderson \& Kilduff, 2009). Investors can be influenced by presentation skills, yet attribute their decisions to fact-based information (Clark, 2008; Mason \& Harrison, 2003). As such, they may make their investments decisions in ways that depart from their goals and reported behavior (Shepherd, 1999; Zacharakis \& Meyer, 2000).

Past work has suggested that visual information can be misattributed and moderate how other information is integrated, contributing to different understandings of concepts, including emotion, deception, and personality (Amabile \& Kabat, 1982; DePaulo et al., 1982; Harrigan et al., 2004; Tanaka et al., 2010). Even when making judgments about music, a domain defined by auditory information, people rely on visual information beyond what they would choose with reflection (Goldin \& Rouse, 2000; Tsay, 2013; Tsay, 2014). For example, when people have access to different types of information, such as auditory versus visual, they may select different candidates altogether, revealing wide discrepancies between what they value and what impacts their judgment. 


\section{VISUALS DOMINATE INVESTOR JUDGMENT}

Recent work has drawn increased attention not only to the interpretation of pitches, but also to the relevant prevalence of different types of social and visual cues (Clarke, Cornelissen, \& Healey, 2019; van Werven, Bouwmeester, \& Cornelissen, 2019). Although visual information can be easy to process (Cardon et al., 2009; Chen et al., 2009), its impact on investor judgment can be variable: some work does not find significant evidence of its impact in the VC setting (Chen et al., 2009), while other work finds that visual information has a significant and positive effect in crowdfunding settings (Li, Chen, Fisher, \& Kotha, 2017).

Through 12 studies using live entrepreneurial pitch competitions, footage, and actual outcomes, this paper adopts methodology from social-perception research (Tsay, 2013) to examine the effect of dynamic visual information on judgment. Taking a streamlined approach, the paper accounts for the impact of visual versus non-visual content of entrepreneurial pitches on judges during pitch competitions. The studies explore the relative impact of dynamic visual cuesincluding gestures, facial expressions, and body language — versus other output—namely, static visual cues, verbal cues, and textual cues. Although static visual information such as gender, ethnicity, facial appearance, and environmental cues have been found to contribute to social judgment (Braun \& Silver, 1995; Chan \& Park, 2015; Krishna \& Schwarz, 2014; Mehta, \& Zhu, 2009; Na, Kim, Oh, Choi, \& O’Toole, 2015), a better understanding of dynamic visual cues can complement these findings and contribute to actionable steps by practitioners.

Pitch competitions are critical funding opportunities that contribute to the viability, sustainability, and growth of startup companies. Such events can vary widely: each pitch can represent and/or be made by individuals or teams; events may focus on a particular industry or goal, such as social entrepreneurship; some are restricted to under 60 seconds, while others have 


\section{VISUALS DOMINATE INVESTOR JUDGMENT}

fewer restrictions on presentation time; some allow the use of slides, while others do not. There is usually one winner per competition, although some include audience favorite/vote winners as well. Most events, especially final rounds, can include both investor judging panels and audiences of up to several hundred people. Judging panels typically devote time to questioning the entrepreneurs. At the end of the competition, the winners are announced, usually after some discussion among the judging panel and calculation of scores.

It is important to understand how entrepreneurs persuade backers to fund them and which types of information are most likely to influence investors. This work thus focuses on evaluations of entrepreneurs' brief pitches. This focus complements previous research suggesting that experts evaluate pitches rapidly and at a fraction of the actual time allowed for pitching (Hofer \& Hall, 1993). The "thin slices" literature broadly suggests that evaluations of dynamic visual cues made after brief exposures to target individuals (of as few as six seconds) correspond well with evaluations made after longer periods of time (Amabile, Krabbenhoft, \& Hogan, 2006; Ambady \& Rosenthal, 1993). Thus, examining thin-slice excerpts can be informative in the specific context of entrepreneurial pitch competitions; angel investors may be able to rapidly pick up on signals and make funding decisions in short time spans (Maxwell \& Lévesque, 2014).

\section{OVERVIEW OF STUDIES}

This work proposes that dynamic visual information significantly impacts selection decisions such as investments, that the effect emerges across levels of expertise, and that it occurs with little conscious awareness. Using decisions and outcomes from entrepreneurial pitch competitions, 12 studies test the impact of visual information on judgments of quality. In these studies, participants receive nine to ten sets of three business pitches per competition. The studies 


\section{VISUALS DOMINATE INVESTOR JUDGMENT}

excerpt portions of actual, live pitch competitions and present variations ranging from minimal information (photograph only) to entire videos of the original pitches. Studies 1 and 2 offer first tests of the relative influence of visual versus auditory information on decision makers. Studies 3 ,

4, 5a, and 5b, along with a supplementary study, present different types and amounts of information to test the impact of visual information. Studies $6 a, 6 b$, and $6 c$ explore mechanisms accounting for any effects of visual information on evaluation. Study 7 investigates more broadly the generalizability of the effects discussed in the preceding studies. Finally, Study 8 offers a test of a possible mechanism accounting for one of the most counterintuitive effects found in this line of research, with implications for interventions.

\section{STUDY 1: DYNAMIC VISUAL INFORMATION AND JUDGMENT}

Study 1 uses recordings from a set of entrepreneurship pitch competitions in the Northeastern United States to extrapolate the relative impact of different types of information on judgments of entrepreneurs' performance. The pitches all featured individual entrepreneurs.

\section{Participants and Design}

Five hundred one participants $\left(M_{\mathrm{age}}=20.79, \mathrm{SD}=2.56 ; 47.3 \%\right.$ male $)$ were drawn from a general participant pool organized by a large university in the Northeastern United States. Participants volunteered in response to e-mails asking them to participate in an hour-long set of studies in a computer lab on campus. In this study, as well as in all following studies, recruitment aimed at sample sizes just beyond the minimum recommended per condition (Simmons, Nelson, \& Simonsohn, 2011), given anticipated attrition from participants who do not fully complete the studies. 


\section{VISUALS DOMINATE INVESTOR JUDGMENT}

Participants completed the survey at computer terminals and then participated in a set of other unrelated studies. Participants were randomly assigned to attend to six-second recordings of either visual-only, sound-only, or video-with-sound excerpts of the same initial segment of each pitch. Using the first seconds of each pitch reduced the likelihood of experimental bias in the choice of segments. Each participant was presented with recordings of three finalists each from nine competitions (for a total of 27 pitch segments) across a range of industries, including development, energy, life sciences, mobile technology, products, and online technology. The nine competitions were presented in random order, and the three finalists within each set were also presented in random order. In this and all other studies presented in this paper, the participants were allowed an unlimited amount of time to consider the materials and thus could have chosen how much time they needed to process the information.

Separate judging panels of industry experts, angel investors, venture capitalists, and experienced entrepreneurs who fund startups evaluated the original competitions from which the recordings were derived. Each entrepreneur had 60 seconds in which to present their business propositions to the judging panels and the wider public audience without the aid of visual slides. The original judges watched all of the pitches live in their entirety, were given time to question the entrepreneurs, and were also given summaries of entrepreneurs' business propositions and brief biographical sketches, which could aid the judges' systematic processing of message content. At the end of each competition, the winners and finalists (runners-up) were announced. Each competition named one winner. Competition judges awarded cash and startup services to the winning entrepreneurs, who were then also introduced to networks of mentors, investors, and potential partners. 


\section{VISUALS DOMINATE INVESTOR JUDGMENT}

For each of the nine competitions, all participating entrepreneurs presented in the same public venue within each competition. As the competitions were based at a university, the eligibility requirements included a current affiliation with the university as a full- or part-time undergraduate or graduate student, which broadly constrained the age range, educational achievements, and general business-casual attire of the presenting entrepreneurs. Within each set of three finalists presented to our study participants, all finalists were of the same gender; this design offered an additional control on gender. For each competition, participants were asked to identify which pitch (of the three they viewed) they thought won the competition. Offering participants the same forced-choice design as in the original competitions - choosing one from among each set of pitches - allows for inferences about the types of information that may have most impacted judges' original decisions. Participants' relatively brief exposure to the pitches also presented a reasonable degree of realism, as the judges in the original pitch competitions were not given much time to consider the pitches before having to make their decisions. After evaluating all nine sets of pitches, participants were asked for their explicit beliefs about what type of information (visuals, sound, other [free response option included]) mattered most in their evaluations of entrepreneurship pitch competitions and in their investment decisions about business plans (“In judging entrepreneurs, what is more important to your evaluation?”).

\section{Explicit Beliefs}

When participants were asked to identify what type of information is most informative in assessing pitches, significantly more participants (63.5\%) cited auditory content, which includes both the business propositions and some nonverbal aspects of pitches, over visual content or other component categories named by participants, $\chi^{2}(2, n=497)=228.95, p<.001$. Thus, when 


\section{VISUALS DOMINATE INVESTOR JUDGMENT}

considering how such decisions are made, people demonstrated a belief that they rely primarily on semantic information and very little on visual information.

The participants ranged in their level of experience with entrepreneurship, from no experience to professional or career-level experience, such as founding startup companies. These levels were tested for external validity; in a separate test conducted on a national online sample ( $N$ $=64$ ), participants were asked to categorize themselves into one of four levels of expertise in entrepreneurship (none, college, startup, professional/career) and to indicate the number of years of experience they had in entrepreneurship. The categories of experience item and years of experience item were highly correlated, $r(64)=.74, p<.001$. Furthermore, t-tests indicated that participants in the upper two levels of experience had significantly more years of experience $(M=$ 8.75) than those in the lower two levels $(M=0.31), t(62)=8.62, p<.001$. These data suggest that those who self-identify as having professional or career-level experience in entrepreneurship have dedicated significantly more time to such pursuits than those who do not and likely share various similarities with the experts who served on the pitch-judging panels. The data presented in this and the following studies are aimed at extrapolating what type of information most impacted the original decisions in the competitions. As such, the design allows for some triangulation upon the most influential cues for evaluations, in the event that participants are able to approximate actual expert decisions at rates significantly above chance.

\section{Results}

In the results in this study and all following studies, comparisons were made by condition, expressed as a percentage rate based on alignment with the original outcomes. Each participant received multiple trials representing different pitch competitions, and for each trial, the choice 


\section{VISUALS DOMINATE INVESTOR JUDGMENT}

response was either aligned or not aligned with the original decision. Averaging across all trials, a percentage rate was calculated for each participant as continuous data. These averages spanned nine sets of stimuli to more broadly test across competitions in a rigorous examination of the possible effect and used the same sets of source stimuli across conditions.

Among participants who received visual-only recordings, 52.2\% identified the actual winners, a rate significantly above chance, $t(171)=11.82, p<.001 ; 43.6 \%$ did so with video-withsound recordings, again above chance, $t(168)=6.73, p<.001$. In comparison, only $35.6 \%$ selected the original winners with sound-only recordings, $t(159)=1.72, p=$ n.s. If participants had selected randomly within each set or trial, their chance levels of identifying the winners would have been $33 \%$. Thus, participants who had access to visual information identified the actual winners at rates significantly above chance and at even higher rates than those who had access to both visuals and sound (Table 1).

Participants who received visual-only stimuli performed significantly better than those receiving sound-only stimuli, $t(330)=7.96, p<.001$, and better than those receiving video-withsound recordings, $t(339)=3.91, p<.001$. Those watching video-with-sound recordings performed significantly better than those listening to sound-only stimuli, $t(327)=3.95, p<.001$. Given that the pitch competitions' original judges had access to both visual and auditory information, the finding that visual-only recordings best allowed participants across levels of expertise in entrepreneurship to identify the actual winners of the pitch competitions suggests that real judges may be most impacted by visual information when making their decisions. These results stand at odds with participants' explicit beliefs about the relative greater value of auditory information over visual cues. 


\section{VISUALS DOMINATE INVESTOR JUDGMENT}

This overall pattern holds even when only those with experience in entrepreneurship are assessed. Significantly more participants with entrepreneurial experience $(60.6 \%)$ believed that auditory content was the most critical signal for the assessment of pitches, $\chi^{2}(2, n=155)=60.17$, $p<.001$. Yet of those who received visual-only recordings, $50.5 \%$ identified the actual winners, a rate significantly above chance, $t(47)=5.45, p<.001$. With video-with-sound recordings, $43.8 \%$ did so, a lower rate but still significantly above chance, $t(54)=4.13, p<.001$. However, with sound-only recordings, only $35.6 \%$ of participants identified the actual winners, a rate not significantly different from chance, $t(51)=0.92, p>.05$. Those with visual-only stimuli performed significantly better than those receiving sound-only stimuli, $t(98)=3.74 p<.001$, and performed marginally significantly better than those receiving video-with-sound recordings, $t(101)=1.67, p$ $=.098$. Those viewing video-with-sound recordings performed significantly better than those listening to sound-only stimuli, $t(105)=2.30, p=.023$. Finally, in each condition, those with entrepreneurial experience did not perform significantly differently from those with no such experience.

Thus, for both novices and experts, visual information appeared to strongly impact the choice of winners, even though investors believed that other channels of information offered more substantive signals about quality. Given that entrepreneurs made their pitches without the aid of visual slides in these competitions, the only dynamic visual information available was what they conveyed nonverbally. Auditory content could be assumed to be the modality that relays the most objective information about the potential value of a business proposition, along with vocal cues such as tone, emphasis, and volume. Yet a discrepancy emerged between what investors report matters in the assessment of entrepreneurs and their pitches (i.e., auditory cues that transmit 


\section{VISUALS DOMINATE INVESTOR JUDGMENT}

tangible, substantive information about business plans) and the information that investors and judges seem to primarily use to choose the best business plans (i.e., dynamic visual cues transmitted by entrepreneurs during the pitch process). This finding highlights that people can be unaware of the extent to which visual information impacts their judgment.

\section{STUDY 2: DYNAMIC VISUAL INFORMATION AND DIRECT JUDGMENT}

Using the same design and set of entrepreneurship pitch competitions, Study 2 builds on the initial investigation by expanding the types of methods tested. In Study 1, participants were not asked which business-plan pitches should win the competitions, based on their own experiences, but rather were asked to guess who actually won the competitions, as determined by the original judges. Such a design may pose some weaknesses, as it entails a longer chain of inferences, including imagining others who were actually involved with the decision, guessing about the decisions of those imagined others, and inferring that the original decision-making process was similar to the participant's process, based on the level of match across the two sets of responses. Further, it is possible that participants hold various assumptions about the original judges that may or may not align with their own decision-making processes; for example, they may assume that others are more vulnerable than they are to cognitive shortcuts that result in biased decisions.

The design of Study 2 shifts to one that is less hypothetical; it streamlines the inferences needed to extrapolate the relative impact of visual versus auditory information on judgments of entrepreneurs' performance. Rather than asking participants to guess which entrepreneurs the judges selected, they are instead now asked for their direct choices of winners; therefore, they are now positioned in the role of judges. I also ask them about what informed their evaluations. 


\section{VISUALS DOMINATE INVESTOR JUDGMENT}

\section{Participants and Design}

One hundred seventeen participants were recruited from a national online sample $(44.0 \%$ female; $M_{a g e}=36.70, S D=12.02$ ) through Amazon Mechanical Turk. This method of data collection is widely used, highly validated, and provides broader samples than most alternatives (Buhrmester, Kwang, \& Gosling, 2011; Kittur, Chi, \& Suh, 2008; Paolacci, Chandler, \& Ipeirotis, 2010; Sorokin \& Forsyth, 2008).

The design was consistent with that used in Study 1; participants were randomly assigned to attend to six-second recordings of either visual-only, sound-only, or video-with-sound excerpts of the same initial segment of each pitch for nine competitions with three finalists each. The key difference was that participants were asked, "Who do you think should win?" instead of "Who won?" the competitions. After evaluating all nine sets of finalists, participants were again asked for their explicit beliefs about what type of information matters most in their evaluations of entrepreneurship pitch competitions and in their investment decisions about business plans.

\section{Explicit Beliefs}

When participants were asked to identify what type of information is more informative in assessing pitches, again, significantly more participants (47.9\%) cited auditory content, which includes both business plans and some nonverbal aspects, over visual content or other categories

named by participants, $\chi^{2}(2, n=108)=26.17, p<.001$. The national online sample showed attitudes consistent with the city-based lab sample in Study 1; people again are more likely to believe that they rely more on semantic information than on visual information.

\section{Results}




\section{VISUALS DOMINATE INVESTOR JUDGMENT}

Replicating the Study 1 results, participants' choices best approached the actual outcomes in pitch competitions in the silent visual-only condition. Of those who received visual-only recordings, $45.0 \%$ identified the actual winners, a rate significantly above chance, $t(36)=3.23, p$ $=.003 ; 39.1 \%$ did so with video-with-sound recordings, again above chance, $t(43)=2.22, p=$ .032. In comparison, only $32.4 \%$ did so with sound-only recordings, $t(35)=-0.40, p=$ n.s. For reference, if participants had selected randomly within each competition, their chance levels of identifying the winners would have been 33\%. Participants who had access only to visual information identified the actual winners at rates significantly above chance and at higher rates even than those who had access to both visuals and sound. This finding again is not well-aligned with participants' explicit beliefs about the relative value of different types of information.

In this more direct test of how people evaluate entrepreneurial pitches, when asked who they themselves would select, participants again were most likely to identify the original winners if they only had access to silent videos. Given that the original competitions provided access to both visual and auditory information, the results here again point to the possibility that judges are most impacted by visual information in their decisions. Even with a more streamlined designone in which it is less likely participants are making assumptions and guesses about others' possible cognitive shortcuts and biases — visuals alone appeared to allow the best correspondence between participants' choices and the original judges' choices. Together, Study 1 and 2 highlight the apparent dominance of visual information in investor judgment.

STUDY 3: A COMPARISON OF CONTENT-RICH TEXT

VERSUS VISUAL PRESENTATION 


\section{VISUALS DOMINATE INVESTOR JUDGMENT}

The earlier studies suggest that even in a domain in which auditory information should offer more directly relevant signals of quality than visual information, visual cues may still have the most impact on decisions. However, participants were offered only brief excerpts from the competition pitches in the previous studies. If those studies limited the amount of relevant and substantive information available through the auditory channel, such constraints could have contributed to lowered rates of identification of the actual competition winners. If so, then allowing participants to access the complete pitch transcripts and written business propositions should result in higher rates of identification of the winners. Making the entire transcription content available presents more concrete and relevant background (Chen et al., 2009) about the business plans. Thus, providing the business propositions in their entirety allows a test of whether the apparent visual dominance found in the earlier studies was simply an artifact of the design or if the original decision makers truly did give more weight to visual information than to substantive information.

\section{Pretest: Explicit Beliefs}

Although the previous studies tested participants' explicit beliefs about the relative importance of auditory versus visual aspects of the entrepreneurs' pitches, some participants reported in their free responses that the content of the pitch was particularly important as a separate category. Accordingly, a separate survey that includes this third category of information assessed what type of information participants believe matters most in their evaluations of entrepreneurial pitches. That is, business plan content is offered as a category separate from other types of auditory information, which include vocal characteristics such as tone, pitch, and clarity of speech.

When participants were asked which category of information is most critical to their decision about which pitch to invest in, the majority identified the business plan content of the 


\section{VISUALS DOMINATE INVESTOR JUDGMENT}

pitch $(82.0 \%)$ over visual content and over auditory content, $\chi^{2}(2, N=161)=177.33, p<.001$. As such, if the original decision makers (competition judges) had been primarily using business-plan content to evaluate pitches, then presenting transcripts with the business plans should allow raters to better identify the actual winners by giving them access to a fuller set of valued information. Focusing on the transcripts also eliminates other information that the auditory channel would have included, such as the tone, emphasis, and volume of vocal output, which may be associated with perceptions of and attributions about the speakers (Hochschild, 1983; Krauss et al., 2002).

Study 3 thus presented a direct comparison between pitch transcriptions (written text only) and visual information to extrapolate what type of information was more influential on decision making in entrepreneurship. This study also presented an opportunity for a discussion of specific types of visual information and how we weight such information when making decisions. It is possible that dynamic visual information might have a more powerful effect on judgments than static visual information (Tsay 2013) - here, text of the business plans outlined in the pitches.

\section{Participants and Design}

One hundred sixty-four participants across levels of experience with entrepreneurship were recruited to participate in an hour-long set of studies in a computer lab on a large university campus in the Northeastern United States. Participants $\left(M_{\mathrm{age}}=35.8, \mathrm{SD}=13.0 ; 46.9 \%\right.$ male $)$ completed the survey at computer terminals and then participated in a set of other unrelated studies. They were randomly assigned to one of two conditions: full transcripts of each individual entrepreneurial pitch, or six-second silent visual excerpts of each pitch. The participants were allowed unrestricted time to make their decisions, and thus were able to choose how much time to process and digest the available information. The pitches were from the same competitions and included the same 


\section{VISUALS DOMINATE INVESTOR JUDGMENT}

pitches as in the previous studies; participants from the earlier studies were excluded from the later studies. As in Study 1, participants were asked to identify the pitch they thought had won in each set.

\section{Results}

Study 3 provided further support for my previous findings that dynamic visual cues have a large impact on decisions in entrepreneurship. Those who were assigned to receive pitch transcripts identified the actual winners $(32.7 \%)$ at rates not significantly different from chance $(33 \%), t(118)=-0.45, p=$ n.s. Yet $42.3 \%$ of those who had received brief silent videos performed significantly better than chance at doing so, $t(45)=3.02, p=.004$. People were significantly more likely to identify the winners through silent videos than through pitch transcriptions, $t(163)=3.33$, $p=.001$; Cohen's $d=0.52$. This suggests that the substantive, semantic content of the pitches did not significantly contribute to the original competition outcomes.

At the same time, participants who had been assigned to the pitch-transcript condition were significantly more satisfied with the evaluation process than those in the silent-video condition, $t(162)=2.01, p=.046$. Those who received the transcripts were also significantly more confident of their choices than those who received the silent videos, $t(162)=2.53, p=.012$. As in the earlier studies, this also suggests that people are likely to believe that their decisions are based more on semantic and substantive information and less on visual cues, and that semantic information alone would allow them to make better decisions.

In supplementary analyses, three independent coders who were blind to the hypotheses and to the original outcomes of the competitions rated the quality of the projects in each pitch based on only the transcriptions. All coders were familiar with entrepreneurship and had graduate-level 


\section{VISUALS DOMINATE INVESTOR JUDGMENT}

educations, and their ratings showed good levels of interrater reliability (Cronbach's alpha $=0.77$ ). The ratings confirmed that the winners and finalists in the pitch sets were from ventures that otherwise exhibited comparable levels of business potential. The ratings of the quality of the pitches based only on the transcriptions did not differ significantly across the original winner versus non-winners in each competition; repeated-measures ANOVAs showed that there were no significant differences across the transcriptions on quality (all $p$ 's $>.05$ ). This was consistent with the earlier results showing that participants were unable to identify the actual winners at rates different from chance.

Further, the supplementary analyses showed a low correlation between the ratings based on transcriptions alone versus the original outcomes, $\eta^{2}=.03$. These analyses accounted for the ex-ante subjective "quality" of the businesses, suggesting that this quality was unlikely to have been endogenously correlated with dynamic visual characteristics. Had the transcript quality correlated well with the assessed quality of dynamic visual cues, there should have been greater correspondence across those two types of excerpts with regard to their respective rates of prompting selection of the original competition winners.

Although people believe that the content of pitches matters most in entrepreneurship, venture capitalists and industry experts appear to be influenced more by dynamic visual information, and more so than they would readily acknowledge. Even when they had access to more information judged to be relevant to evaluation, in the form of pitch transcripts, study participants were unable to identify the actual winners of the competitions. This suggests that the original judges may have differentiated among pitches using dynamic visual information and were more persuaded by factors that had less to do with pitch content. 


\section{VISUALS DOMINATE INVESTOR JUDGMENT}

\section{STUDY 4: A TEST OF VOLUME OF INFORMATIONAL CONTENT}

The previous studies highlight the power of dynamic visual information over other types of information to influence judgments of entrepreneurial pitches. However, isolating elements of the presentations to text transcripts neglects the possibility that having a fuller set of auditory information could be most relevant to evaluators. For example, the auditory channel could include additional information that people might value beyond the content of the business plans, such as which parts of the pitch entrepreneurs emphasized through their voices and thus valued more (Hochschild, 1983; Krauss et al., 2002). In addition, although the use of the same sections from each pitch across conditions controlled for some potential confounds, it could be that those sections were unequally informative in terms of content, resulting in distortions in participant choices toward the visual.

Study 4 thus offered a strong test of the possible alternative explanation that visual information is more important than auditory information because the visual modality reveals more volume of information or more usable information than the auditory channel. Under the constraints of limited time, visual information may be more readily processed, or auditory information may fail to convey adequate content for appropriate judgment. A dependence on visual cues may be accentuated in contexts that present only impoverished information. Thus, rather than testing brief excerpts of pitches, as in the earlier studies, Study 4 examined judgments of videos and audio of the entire pitches originally presented during the nine competitions.

\section{Participants and Design}

Ninety-three participants across levels of experience with entrepreneurship were recruited from a national online sample through Amazon Mechanical Turk. Participants $\left(M_{\mathrm{age}}=36.6, \mathrm{SD}=\right.$ 


\section{VISUALS DOMINATE INVESTOR JUDGMENT}

$12.6 ; 47.4 \%$ male) were randomly assigned to one of three conditions: visual-only versions of the entire pitches, sound-only versions of the entire pitches, or video-with-sound recordings of the entire pitches. As in the previous studies, three pitches from each of the same nine competitions were included. As in Studies 1 and 3, participants were asked to identify the pitch that they thought had won each competition.

\section{Results}

Of those who received visual-only recordings, $50.6 \%$ identified the actual winners, a rate significantly above chance, $t(33)=5.16, p<.001 ; 46.8 \%$ did so with video-with-sound recordings, again above chance, $t(32)=4.26, p<.001$. In comparison, only $40.2 \%$ did so with sound-only recordings, $t(28)=2.31, p=.029$. Those with visual-only stimuli again performed significantly better than those receiving sound-only stimuli, $t(61)=2.28, p=.026$. As before, if participants had selected randomly within each competition, their chance levels of identifying the winners would have been $33 \%$.

Whether brief excerpts or entire pitches were presented, participants were able to identify the actual winners only when visual cues were available. The inclusion of more auditory content seemed to allow participants to become better at identifying the actual winners, suggesting that longer periods of evaluation may reveal more useful information with sound excerpts. However, the group that received visual-only excerpts still performed best at identifying the winners. The findings indicate that across a wide range of sensory information and a wide range of volume of information, the visual modality dominates judgment.

It is possible that visual information generally is more dominant in human perception and is communicated at much greater speed relative to verbal information. Evaluators may begin to 


\section{VISUALS DOMINATE INVESTOR JUDGMENT}

process verbal content after visual cues have shaped their thinking in ways that may not be altered, regardless of the substance of the arguments. For example, conveying the complexity of experience can require a verbal conversation, but a candidate's visual cues can instantaneously determine evaluators' interest in and openness to engaging with the more substantive information.

\section{STUDY 5A: DYNAMIC VISUAL INFORMATION AND ENTREPRENEUR JUDGMENT}

To better establish the ecological, real-world importance of the phenomenon of an apparent visual dominance, Study 5 further tests expert judgment by focusing on participants who identify as having experience with entrepreneurial firms. Because their decisions may arguably have a more potent impact on entrepreneurial ventures, as people who regularly make such decisions in the real world, it is important to assess whether they react similarly to judgments of pitch competitions. Study 1 began this investigation, but was limited to more basic questions about entrepreneurship experience.

\section{Participants and Design}

One hundred fifty expert participants were recruited from a national online sample (46.0\% female; $\left.M_{\text {age }}=34.68, S D=10.66 ; M_{\text {years experience }}=5.48, S D=5.89\right)$ through Amazon Mechanical Turk. All who failed to comply with the instructions about participating only if they had experience in entrepreneurship were excluded. Similarly, those who identified as having had experience and yet also indicated having zero years of experience were also excluded.

The design was consistent with that used in Study 4; participants were randomly assigned to one of three conditions: visual-only versions of the entire pitches, sound-only versions of the entire pitches, or video-with-sound recordings of the entire pitches. After the participants evaluated 


\section{VISUALS DOMINATE INVESTOR JUDGMENT}

which entrepreneur in each competition they would choose as the winner, participants were again asked for their explicit beliefs about what type of information matters most in their evaluations during entrepreneurship pitch competitions and in their investment decisions about business plans.

\section{Explicit Beliefs}

When participants were asked to identify what type of information is more informative in assessing pitches, significantly more expert participants $(50.7 \%)$ cited auditory content, which includes both the business propositions and some nonverbal aspects, over visual content or other component categories, $\chi^{2}(2, n=150)=43.32, p<.001$. Experts again demonstrated a belief that they rely primarily on semantic information rather than on visual information.

\section{Results}

Of those who received visual-only recordings, $42.2 \%$ identified the actual winners, a rate significantly above chance, $t(54)=3.70, p=.001 ; 41.6 \%$ did so with video-with-sound recordings, again above chance, $t(50)=3.23, p=.002$. In comparison, only $33.3 \%$ selected the original winners with sound-only recordings, $t(44)=0.00, p=$ n.s. For sake of comparison, if participants had selected randomly within each set or trial, their chance levels of identifying the winners would have been $33 \%$. Participants who had access to only visual information identified the actual winners at rates significantly above chance.

Participants who received visual-only stimuli performed significantly better than those receiving sound-only stimuli, $t(97)=2.63, p=.010$. With video-with-sound recordings, participants were again no better than those receiving only silent videos, $t(104)=-0.17, p=$ n.s. Those watching video-with-sound recordings performed significantly better than those listening 


\section{VISUALS DOMINATE INVESTOR JUDGMENT}

to sound-only stimuli, $t(93)=2.38, p=.019$. These results again stand at odds with participants' explicit beliefs about the relative value of different types of information.

Given that this study may offer greater relevance and external validity, with the full pitches being made available to participants with entrepreneurship experience, additional quantitative and qualitative analyses were conducted to discern the reasoning strategies participants used and to test any differences in cognitive attention or effort that might have impacted how participants processed the stimuli and made their choices.

In a first analysis, the length of time participants spent on the study was used as a proxy for cognitive attention or effort. There were no significant differences in how participants responded to the type of stimuli, $F(2,148)=0.74, p=$ n.s. Those who received silent videos $(M=$ 28.33, $S D=13.80$ ) did not spend significantly more time (minutes) on their decisions than those who received audio recordings, $(M=30.72, S D=17.74), t(98)=-0.76, p=$ n.s., or those who received video-with-sound recordings $(M=32.70, S D=23.33), t(105)=-1.19, p=$ n.s. Those who received audio recordings did not spend significantly more time on their decisions than those who received video-with-sound recordings, $t(93)=-0.46, p=$ n.s.

When participants were asked with a free-response item to answer the question "How did you make your decisions about the entrepreneurs?", they identified a range of factors as contributing to their conscious evaluation, including biographical information about and impressions of the target individual (confidence, passion, potential, skill, track record, and experience), the presentation, the business proposal, the industry and market, and the evaluators' own intuition. A basic content analysis coded all independent mentions of the use of visual information and revealed that of participants who received the video-with-sound excerpts, only 


\section{VISUALS DOMINATE INVESTOR JUDGMENT}

$41 \%$ of participants explicitly recognized that they were factoring visual information into their evaluations of the target entrepreneur. This complements the earlier findings highlighting a discrepancy between the substance people consciously value and the visuals they actually privilege.

\section{STUDY 5B: DYNAMIC VISUAL INFORMATION AND INVESTOR JUDGMENT}

Despite the fact that only participants who had experience with entrepreneurship were selected for Study 5a and that the results are consistent with those of novices, it was possible that the sample obtained did not have extensive investment experience. Thus, Study $5 \mathrm{~b}$ further tests expert judgment by focusing on angel investors, repeat crowdfunding investors, and others who identify as having extensive other experience investing in startups. This study also used a different platform for recruitment.

\section{Participants and Design}

One hundred eighty-seven investors were recruited from a national online sample $(34.8 \%$ female; $M_{\text {age }}=42.24, S D=13.92 ; M_{\text {years experience }}=13.80, S D=11.47$ ) through Qualtrics Panels. All who failed to comply with the instructions about participating only if they had experience in investing were excluded. As an additional filter for expertise, participants were also asked how they would describe their experience with investments. Of the participants who passed attention checks and were included, $42 \%$ identified as being angel investors, 53\% as repeat crowdfunding investors, $48 \%$ as having extensive other experience investing in startups, and $31 \%$ as identifying as having multiple categories of investment experience.

The design was consistent with that used in Study 2; participants were randomly assigned to one of three conditions: visual-only versions of the pitches, sound-only versions of the pitches, 


\section{VISUALS DOMINATE INVESTOR JUDGMENT}

or video-with-sound recordings of the pitches. Due to the constraints of the recruitment platform and the advice to limit the study length to no more than 20 minutes, the shorter versions of the pitches were used. This goal was achieved, with participants completing the study in an average of 17.58 minutes $(S D=16.50)$. After the participants evaluated which entrepreneur in each competition they would choose as the winner, participants were again asked for their explicit beliefs about what type of information matters most in their evaluations during entrepreneurship pitch competitions and in their investment decisions about business plans.

\section{Explicit Beliefs}

When participants were asked to identify what type of information is more informative in assessing pitches, significantly more expert participants (47.1\%) cited auditory content, which includes both the business propositions and some nonverbal aspects, over visual content or other component categories, $\chi^{2}(2, n=187)=56.29, p<.001$. Experts again demonstrated a belief that they rely primarily on semantic information rather than on visual information. The participants also endorsed a rapid evaluation of entrepreneurial pitches; when asked "How many minutes do you think are needed to make an informed decision about which entrepreneur should win?", they indicated that an average of $15.92(S D=26.58)$ was sufficient.

\section{Results}

Of those who received visual-only recordings, $43.8 \%$ identified the actual winners, a rate significantly above chance, $t(66)=4.92, p<.001$. In comparison, $36.2 \%$ did so with video-withsound recordings, not significantly above chance, $t(64)=1.33, p=$ n.s.; notably, only $27.7 \%$ selected the original winners with sound-only recordings, $t(54)=-3.28, p=.002$, which is significantly below chance (Figure 1). For sake of comparison, if participants had selected 


\section{VISUALS DOMINATE INVESTOR JUDGMENT}

randomly within each set of competitions, their chance levels of identifying the winners would have been $33 \%$.

Participants who received visual-only stimuli performed significantly better than those receiving sound-only stimuli, $t(120)=5.71, p<.001$. In supplementary analyses, an item analysis was conducted to investigate for any systematic variations across sets. The item analysis indicated that the effect held across all nine competitions, $t_{2}(8)=4.14, p=.003$. With only silent videos, participants also performed significantly better than those receiving video-with-sound recordings, $t(130)=2.48, p=.015$. Those watching video-with-sound recordings performed significantly better than those listening to sound-only stimuli, $t(118)=3.00, p=.003$. These results again are inconsistent with participants' explicit beliefs about the relative value of different types of information; even investors do not appear to be fully aware of how much visual information impacts their decisions.

With a panel of participants indicating significant levels of experience in investing in startups, additional quantitative and qualitative analyses were conducted again to investigate the participants' reasoning. In a first analysis, the length of time participants spent on the study was used as a proxy for cognitive attention or effort. There were no significant differences in how participants responded to the type of stimuli, $F(2,184)=0.74, p=$ n.s. Those who received silent videos $(M=19.35, S D=24.90)$ did not spend significantly more time (minutes) on their decisions than those who received audio recordings $(M=17.50, S D=10.22), t(120)=0.52, p=\mathrm{n} . \mathrm{s}$; or those who received video-with-sound recordings $(M=15.85, S D=7.58), t(130)=1.09, p=$ n.s. Those who received audio recordings did not spend significantly more time on their decisions than those who received video-with-sound recordings, $t(118)=1.02, p=$ n.s. 


\section{VISUALS DOMINATE INVESTOR JUDGMENT}

Investors, like experienced entrepreneurs, identified a range of factors as contributing to their evaluation, including impressions of the target individual (confidence, passion, potential, skill, track record, and experience), the presentation, the business proposal, the industry and market, and the evaluators' own intuition. A basic content analysis coded all independent mentions of the use of visual information and revealed that of participants who received the video-withsound excerpts, only $38.5 \%$ of participants explicitly recognized that they were factoring visual information into their evaluations of the target entrepreneur, relative to $60.0 \%$ who cited semantic and substantive information in their explanations for how they evaluate entrepreneurs, $Z=-2.11$, $p=.035$. This complements the earlier findings with novices and entrepreneurs highlighting a discrepancy between the substance people consciously value and the visuals they actually privilege.

It is possible that in the absence of one type of stimuli, participants increased their attention to other signals that were available. The design used may have prompted participants to devote more cognitive attention to the otherwise deprived stimuli presented to them, such that their reports of how they made their choices may not necessarily be precisely those used by the original judges. That said, even if visual and auditory cues demand significantly different levels of cognitive workload to process the relative information, the original decision makers had access to both types

of information. Increased attention to visual cues thus cannot be solely due to the absence of auditory stimuli. The pattern that emerged through the earlier studies suggest that visual information strongly influences judgments of entrepreneurs, even though experts believe other channels of information offer more substantive signals about quality. For example, for entrepreneurs, adding auditory and semantic information back to the visuals did not contribute 


\section{VISUALS DOMINATE INVESTOR JUDGMENT}

predictive value to how well experts were able to select the original winners. In fact, for investors, providing auditory and semantic information actually led to the selection of different "winners" altogether, as compared to the targets who were originally chosen as winners. Even those who are likely to be in the position of making such decisions on a regular basis and have full access to the entire set of information may be less aware of how much visual information can impact their judgment.

\section{STUDIES 6A/6B/6C: CHARACTERISTICS CONVEYED THROUGH VISUAL CUES}

This set of studies explores the specific cues that accounted for judges' visually based evaluations in the earlier studies. Visible passion, due to its associations with entrepreneurial activity (Cardon et al., 2009; Cardon et al., 2005; Li et al., 2017; Smilor, 1997), may contribute to mental representations of the successful entrepreneur and serve as a mechanism underlying the dominance of visual information on decision making. Given that facial expressions of emotion can serve as a visual language, the quality of passion may be more salient through sight than through other sensory channels (Jack et al., 2016), even if other modalities are better able to deliver relevant and substantive content about business propositions. These studies test whether greater visible passion is related to expert choices of entrepreneurial pitches for funding. Study 6a first assesses several visible characteristics commonly associated with entrepreneurial activity and success: passion, confidence, uniqueness, and physical attractiveness.

\section{STUDY 6A: TESTS OF WHAT VISUALS CONVEY}

\section{Participants and Design}

Thirty-four participants with different levels of experience with entrepreneurship were recruited to participate in an hour-long set of studies in a computer lab on a large university campus 


\section{VISUALS DOMINATE INVESTOR JUDGMENT}

in the Northeastern United States. Participants completed the survey at computer terminals and then participated in a set of other unrelated studies. To explore the factors that drove the visually based decisions observed in the earlier studies, I presented visual-only recordings from the same stimuli set of nine competitions used in the earlier studies. The participants $\left(M_{\text {age }}=39.55, \mathrm{SD}=\right.$ $13.29 ; 45.5 \%$ male) evaluated each of the nine sets of three finalists.

Participants were asked to determine which individual they found to be most confident, passionate, unique, and physically attractive (for each attribute) in each of the nine competitions. These terms were not specifically defined for participants, and the forced choice design is consistent with those used in previous work (Tsay, 2013). Repeat choices were permitted. These characteristics had been among the most frequently cited by the participants in the earlier studies as having contributed to their choices; testing these items directly in Study 6a would allow me to explore which characteristics contributed most to the apparent visual dominance in decisions.

The items are consistent with work about traits that tend to lead to favorable judgments (Beehr \& Gilmore, 1982; Biddle \& Hamermesh, 1998; Dion et al., 1972; Navis \& Glynn, 2011). Recent research highlights the ways in which entrepreneurial passion, characterized by intense positive feelings and meaningful engagement, can contribute to performance through effects on communication, persistence, creative problem solving, and opportunity recognition (Cardon et al., 2009). Passion may drive venture capitalists' evaluations (Mitteness, Sudek, \& Cardon, 2012), given that entrepreneurs' passion contributes to venture growth by increasing commitment (Vallerand et al., 2003), preparedness (Chen et al., 2009), resilience, persistence (Bird, 1989; Cardon et al., 2005), competence, motivation (Smith et al., 2001), initiative (Bierly et al., 2000), 


\section{VISUALS DOMINATE INVESTOR JUDGMENT}

self-efficacy (Baum \& Locke, 2004), and likelihood of developing and executing opportunities (Shane et al., 2012).

Because of such associations, decision makers may use perceived passion as an indicator of quality even when it is not accompanied by more relevant metrics of quality. As perceived passion is not necessarily well aligned with felt (Cardon et al., 2009) or displayed passion (Cardon, 2008; Zott \& Huy, 2007), the current work focuses on subjective perceived passion as the factor most proximate to funding and investment decisions (Carter \& Van Auken, 1992; MacMillan et al., 1987).

If decision makers use passion as a proxy for quality, a broader heuristic based on visuals may help account for how people gauge the quality of business pitches at a more basic level. Different facets of passion may be reflected in both verbal and nonverbal expressions, evident both in entrepreneurs' business plans and in the way they respond to evaluators during their presentations (Chen et al., 2009). However, as passion may be more perceptible through sight than sound (Tsay, 2013), dynamic visual information may allow clearer differentiation among entrepreneurs' pitches, relative to other cues.

Additional visible aspects of entrepreneurs' presentations may also contribute to judges' selection of winners. Confidence is linked with greater resilience, positive emotions, and social support, all of which contribute to greater likelihood of success (Hayward et al., 2010; Hmieleski \& Baron, 2009). Novelty, innovation, and uniqueness are closely tied to how practitioners think about the nature of entrepreneurship (Gartner, 1990; Navis \& Glynn, 2011). Physical attractiveness can also contribute to whether pitches are persuasive (Brooks et al., 2014). 


\section{VISUALS DOMINATE INVESTOR JUDGMENT}

As these characteristics are often visible, visual information may allow people to identify the winners of pitch competitions by using visual characteristics as proxies for quality. I do not suggest whether such visual information should be used as a proxy of presentation or whether it conveys quality; rather, I simply aim to determine whether such characteristics are likely to have significantly impacted decision makers' evaluations. For example, it is possible that visible passion is associated with quality and thus used as a signal of quality even if actual quality is not present.

\section{Results}

Of the items assessed (confident, passionate, unique, and physically attractive), assessments of entrepreneurs' passion best approximated (58.8\%) judges' original pitch decisions, at rates significantly higher than chance $(33 \%), t(40)=6.56, p<.001$. This suggests that the original expert judges may have been significantly influenced by entrepreneurs' visible passion. Confidence was also important in the judgment of pitches $(48.4 \%), t(40)=4.05, p<.001$. There was a significant and moderate correlation between the passion and confidence items, $\phi=.320$. The uniqueness (35.3\%) and physical attractiveness (34.4\%) items were not significant in allowing participants to identify the actual winners, $t(40)=0.54, p=$ n.s., $t(40)=0.38, p=$ n.s., respectively. Similarly, a separate supplementary study (S1) using photographs of the same entrepreneurs showed that participants were unable to identify the actual winners through static visual information such as physical attractiveness, race, or gender, $t(35)=1.53, p=$ n.s.

The items in Study 6a allowed for rates of identification of actual competition winners that were marginally significantly higher than those achieved by directly asking participants to identify 


\section{VISUALS DOMINATE INVESTOR JUDGMENT}

the winners of the same competitions, $t(210)=1.76, p=.081$. Indeed, identifying the most passionate entrepreneurs through visual information alone allowed for better approximations of the actual competition outcomes than any condition in the earlier studies, in which participants were explicitly asked to identify who they thought the winners had been or should be. It should be noted that the visual cues that are perceived as markers of passion are unlikely to be subject to expertise or training in entrepreneurship, given that the item asking participants to identify the most passionate individual did not give any domain-specific definition of passion; rather, the design allowed participants to apply their own concept of passion to their choices.

These results suggest that dynamic visual information accounts for a large proportion of the variance in decision makers' selections. Static visual information, such as cues about demographic categories, did not allow participants to identify the original competition winners. These findings are consistent with other work that has revealed varied effects in the relationship between the race and sex of decision makers and candidates (Huffcutt, 2011).

\section{STUDY 6B: RELATIVE SALIENCE OF PASSION THROUGH VISUALS AND SOUND}

The results of the earlier studies suggest that visuals may have particularly impacted investor decision making through passion. A follow-up study tested the possibility that passion can be more effectively communicated through visuals than through auditory content. In Study 6b, 196 participants were recruited from a national online sample ( $46.9 \%$ female; $M_{\text {age }}=33.57, S D=$ 9.82) through Amazon Mechanical Turk. Participants were randomly assigned to either visualonly or sound-only recordings from the same stimuli set used in the earlier studies, and then asked to determine which finalist they found to be most passionate in each of the nine competitions. For participants who only had access to visual cues, assessments of entrepreneurs' passion 


\section{VISUALS DOMINATE INVESTOR JUDGMENT}

approximated judges' original pitch decisions at a rate $(60.2 \%)$ significantly higher than chance $(33 \%), t(98)=15.01, p<.001$. However, participants who had access to the sound recordings did not appear to differentiate across each set of finalists on the dimension of passion; their assessments of entrepreneurs' passion mapped with $33.4 \%$ of the judges' original pitch decisions at rates not significantly different than chance, $t(96)=0.08, p=.936$. Further, participants only given visuals were significantly more able than those provided sound recordings, through the dimension of passion, to approximate the original judges' decisions, $t(194)=11.67, p<.001$. This suggests that the original expert judges were influenced by entrepreneurs' passion, which is more salient through visuals than sound.

\section{STUDY 6C: FURTHER TEST OF VISIBLE PASSION}

Based on the findings from Study $6 \mathrm{a}$ and $6 \mathrm{~b}$ that pointed to the importance of perceived passion over other characteristics tested, Study $6 \mathrm{c}$ focused on further testing the construct of passion using psychometrically valid measures (Cardon et al., 2009; Cardon et al., 2013; Chen et al., 2009; Li et al., 2017), which may better allow comparisons with existing studies in the field. Adapting one of the more established scales in the field, the Perceived Passion Scale (Chen et al., 2009), Study 6c allowed participants to again evaluate all of the entrepreneurial pitches used in my previous studies.

Participants were assigned to view the visual-only excerpts of the initial segments of each pitch. Without knowing who the actual winners of each competition were, 52 participants recruited through a national online sample $\left(42.3 \%\right.$ female; $\left.M_{\text {age }}=33.98, S D=11.49\right)$ evaluated each candidate on five items relevant to affective passion on a five-point scale (1, "not at all," to 5, "frequently"): "the presenter(s) had energetic body movements," "the presenter(s) had rich body 


\section{VISUALS DOMINATE INVESTOR JUDGMENT}

language," "the presenter(s) showed animated facial expression," "the presenter(s) used a lot of gestures," and "the presenter's face lit up when he talked."

Despite being blind to the results of the competitions, participants rated the winners $(M=$ $2.38, S D=0.58)$ as significantly more passionate than the non-winners $(M=1.66, S D=0.61)$, $t(51)=18.07, p<.001$. These findings, consistent with those detailed earlier in Studies 6a and 6b, further highlight how visual cues of affective passion appear to drive the original judges' decisions about entrepreneurial pitches.

\section{STUDY 7: A TEST OF GENERALIZABILITY}

In the previous ten studies, a range of tests and types of materials from live entrepreneurship pitch competitions revealed that visuals appeared to dominate investor judgment. Although the overall pattern throughout the studies suggests that the effects can be found consistently, it was important to determine whether the effects would still emerge if different sets of entrepreneurial pitch competitions were tested or if some of the effects might have been unique to the set of competitions examined in the initial ten studies. Given the range of different types of competitions in the field, Study 7 draws on a new set of competition recordings and real outcomes to test a broader array of competitions that allows a better understanding of the generalizability of the visual dominance of visual judgment.

First, a set of two research assistants, blind to the findings of the earlier studies, searched for new entrepreneurial pitch competitions. From this search, materials from three finalists of each of ten competitions were excerpted, after controlling for the overall visual perspective of the recording (similar distance and angle, no slide content) and the gender and attire of entrepreneurs within each competition. Within each competition, the entire pitches of all three finalists were 


\section{VISUALS DOMINATE INVESTOR JUDGMENT}

excerpted in their entirety. Notably, this new set of ten pitch competitions offered two key novel aspects: (1) competitions based on longer pitch duration limits, ranging from 60 seconds to 3 minutes; and (2) competitions in which the finalists included all female entrepreneurs.

\section{Participants and Design}

One hundred forty-eight participants were recruited from a national online sample $(46.0 \%$ female; $M_{a g e}=35.05, S D=11.29 ;$ Mears experience $\left.=5.76, S D=8.84\right)$ through Amazon Mechanical Turk. Participants were randomly assigned to one of three conditions: visual-only versions of the entire pitches, sound-only versions of the entire pitches, or video-with-sound recordings of the entire pitches. After the participants evaluated which entrepreneur in each competition they would choose as the winner, participants were asked for their explicit beliefs about what type of information matters most in their evaluations during entrepreneurship pitch competitions and in their investment decisions about business plans.

\section{Explicit Beliefs}

When participants were asked to identify what type of information is more informative in assessing pitches, significantly more participants (54.1\%) cited auditory content, which includes both the business propositions and some nonverbal aspects, over visual content or other component categories, $\chi^{2}(2, n=148)=40.31, p<.001$. As before, people believe that they rely primarily on semantic information rather than on visual information.

\section{Results}

Of those who received visual-only recordings, $47.9 \%$ identified the actual winners, a rate significantly above chance, $t(60)=8.45, p<.001 ; 40.4 \%$ did so with video-with-sound recordings, again above chance, $t(45)=2.59, p=.013$. In comparison, only $36.1 \%$ selected the original winners 


\section{VISUALS DOMINATE INVESTOR JUDGMENT}

with sound-only recordings, $t(40)=1.18, p=$ n.s. For sake of comparison, if participants had selected randomly within each set or trial, their chance levels of identifying the winners would have been $33 \%$. Participants who had access to only visual information identified the actual winners at rates significantly above chance.

Participants who received visual-only stimuli performed significantly better than those receiving sound-only stimuli, $t(100)=4.14, p<.001$. With silent videos, participants were again better than those receiving video-with-sound recordings, $t(105)=2.40, p=.018$. Those watching video-with-sound recordings did not perform significantly better than those listening to soundonly stimuli, $t(85)=1.19, p=$ n.s. These results again stand at odds with participants' explicit beliefs about the relative value of different types of information.

These results also stand in striking contrast with how participants felt about the recordings they received. That is, the type of recording significantly impacted how satisfied and confident the participants were with their choices, $F(2,145)=3.51, p=.033 ; F(2,145)=12.61, p<.001$; respectively. Participants were significantly more satisfied making judgments based on videowith-sound recordings $(M=80.22, S D=14.43)$ than on silent videos $(M=69.97, S D=24.02)$, $t(105)=2.56, p=.012$. Those who received the sound-only recordings expressed satisfaction levels between those in the other two conditions $(M=76.85, S D=20.45)$, with results not significantly different from those with video-with-sound recordings, $t(85)=-0.89, p=\mathrm{n} . \mathrm{s}$; or silent videos, $t(100)=1.51, p=$ n.s. The patterns were even clearer for evaluations of confidence in judgment. Participants were significantly more confident making judgments based on videowith-sound recordings $(M=80.41, S D=16.00)$ than based on silent videos $(M=59.82, S D=$ $27.42), t(105)=4.54, p<.001$. They were also significantly more confident making judgments 


\section{VISUALS DOMINATE INVESTOR JUDGMENT}

based on sound recordings $(M=76.39, S D=20.90)$ than based on silent videos, $t(100)=3.28, p$ $=.001$. Confidence in judgment was not significantly different between those who received the video-with-sound recordings and those who received the sound recordings, $t(85)=1.01, p=$ n.s.

Turning to the four competitions that each featured all female entrepreneurs, the effects were consistent with — and perhaps even more robust than — those established earlier in this paper. Of those who received visual-only recordings, $53.7 \%$ identified the actual winners, a rate significantly above chance, $t(60)=8.03, p<.001$. In comparison, only $35.3 \%$ did so with videowith-sound recordings, again above chance, $t(45)=0.46, p=$ n.s.; and $31.1 \%$ selected the original winners with sound-only recordings, $t(40)=-0.61, p=$ n.s.

Participants who received visual-only stimuli performed significantly better than those receiving sound-only stimuli, $t(100)=5.23, p<.001$. With silent videos, participants again performed better than those receiving video-with-sound recordings, $t(105)=3.84, p<.001$. Those watching video-with-sound recordings did not perform significantly better than those listening to sound-only stimuli, $t(85)=0.73, p=$ n.s.

Overall, Study 7 suggests that even using an entirely new set of ten entrepreneurship pitch competitions, which included pitches of longer duration and competitions with all-female finalists, the dominance of visuals on investor judgment persisted and appears to be generalizable across a range of competition settings.

\section{STUDY 8: A TEST OF THE IMPACT OF COGNITIVE LOAD}

Across the previous studies, the primacy of visuals in investor judgment consistently emerged. A more counterintuitive pattern that emerged were the higher rates of alignment with the original judging outcomes with silent videos, over and above rates achieved with videos including 


\section{VISUALS DOMINATE INVESTOR JUDGMENT}

sound. This effect appeared repeatedly and through two sets of different stimuli encompassing 19 different entrepreneurial pitch competitions.

This pattern posed new questions for investigation, given that it may not be anticipated by theories about communication channel richness (Daft \& Lengel, 1986). Across studies, it appeared that the provision of more information actually led to greater deviations from original decisions. Such findings are puzzling, given that the visuals with sound excerpts offered the closest approximations of the original conditions under which the investors made their decisions during the entrepreneurial pitch competitions.

However, it may be that there are some differences between the video-with-sound conditions and the original conditions under which the judges made their decisions. In the various studies in the current work, participants were focused on finalists and, for the most part, had a more finite set of information to process. In contrast, the original judges typically evaluated all candidates and also likely encountered many other sources of information and distraction, including and not limited to peer judges, audiences, and any spontaneous or accidental events that may have occurred that were not part of the scheduled evaluative components.

Thus, the original judging contexts might be thought of as decisions made under cognitive load, relative to the focused efforts enabled in the experimental settings. This could account for how the original judges reverted to a vision heuristic, or visually based shortcut, under conditions of load; in contrast, the experimental setting actually imposed less cognitive constraints, allowing the participants to factor in auditory content about the business proposals, ironically leading them away from alignment with the original judges' decisions. To test this possibility, the current study offered a replication of the effects found with visual-only and video-with-sound excerpts, as in the 


\section{VISUALS DOMINATE INVESTOR JUDGMENT}

new set of stimuli presented in Study 7. In a third condition, the video-with-sound excerpts were presented, but only after participants experienced significant cognitive load that was meant to simulate some of the constraints the original judges may have faced.

\section{Participants and Design}

One hundred forty-eight participants were recruited from a national online sample $(46.0 \%$ female; $M_{a g e}=35.05, S D=11.29 ;$ Mears experience $\left.=5.76, S D=8.84\right)$ through Amazon Mechanical Turk. Participants were randomly assigned to one of three conditions: visual-only versions of the entire pitches, video-with-sound recordings of the entire pitches, and video-with-sound recordings of the entire pitches after cognitive load. This third condition was implemented through the addition of two tasks: counting backwards in 7's from 881, and remembering a 10-digit number (Boekaerts, 2017; Maranges, Schmeichel, \& Baumeister, 2017). As in Study 7, the participants evaluated which entrepreneur in each competition they would choose as the winner.

\section{Results}

Of those who received visual-only recordings, $48.8 \%$ identified the actual winners, a rate significantly above chance, $t(67)=7.27, p<.001 ; 41.7 \%$ did so with video-with-sound recordings, again above chance, $t(64)=4.74, p<.001$. With silent videos, participants performed better than those receiving video-with-sound recordings, $t(131)=2.57, p=.011$. These are consistent with and thus replicate the findings from Study 7.

Under cognitive load, $47.3 \%$ of participants who received video-with-sound recordings identified the actual winners, a rate significantly above chance, $t(43)=6.67, p<.001$. Importantly, they did not perform differently than those who received visual-only stimuli, $t(110)=-0.49, p=$ 


\section{VISUALS DOMINATE INVESTOR JUDGMENT}

n.s. Indeed, they actually were significantly more able to identify the original winners relative to participants who received the same video-with-sound recordings without cognitive constraints, $t(107)=2.03, p=.045$.

The impact of cognitive load was also apparent in participants' level of satisfaction with and confidence in their choices, and provides a level of triangulated data to further support the possibility that cognitive load shifts decision making towards a process that may be more visually based. Consistent with how load shifted choices toward visually based outcomes, load also decreased satisfaction and confidence in decisions in a similar way prompted by having access to only visual stimuli.

Participants were significantly more satisfied making judgments based on video-withsound recordings $(M=83.88, S D=14.22)$ than on silent videos $(M=76.97, S D=24.02), t(131)$ $=2.00, p=.047$. However, this was no longer the case with the same video-with-sound recordings under load $(M=73.32, S D=17.22)$, with results not significantly different from those with silent videos, $t(110)=0.87, p=$ n.s. Those who received video-with-sound recordings were significantly more satisfied than those receiving the same recordings under load, $t(107)=3.49, p=.001$.

The results in levels of confidence in judgment paralleled those in levels of satisfaction. Participants were significantly more satisfied making judgments based on video-with-sound recordings $(M=82.23, S D=18.62)$ than on silent videos $(M=67.01, S D=28.51), t(131)=3.63$, $p<.001$. Again, this was no longer the case with the same video-with-sound recordings under load $(M=74.32, S D=19.90)$, with results not significantly different from those with silent videos, $t(110)=1.48, p=$ n.s. Those who received video-with-sound recordings were significantly more satisfied than those receiving the same recordings under load, $t(107)=2.12, p=.037$. 


\section{VISUALS DOMINATE INVESTOR JUDGMENT}

Overall, Study 8 helps clarify one likely explanation for some of the counterintuitive findings observed throughout the current work. Participants who received more information in the form of videos with sound actually aligned less well with the original outcomes because the original judges likely relied on a vision heuristic during the evaluation setting of the competitions. Once greater cognitive load was imposed on participants, their decisions aligned better with those of the original judges. The results of this final study have important implications for the environments we create for decision making and suggests possible interventions to steer us toward more consistent and value-aligned decisions.

\section{GENERAL DISCUSSION}

Across a twelve-study examination of investor decisions about entrepreneurial pitch competitions, visual information emerges as highly influential in judgment, to the extent that it appears to dominate auditory and semantic information. Although people generally believe that business plans are better assessed through substantive content, participants were not able to identify the original winners of actual entrepreneurship pitch competitions through auditory content or transcriptions. In contrast, those with exposure to only dynamic visual information were significantly more able to identify the winners. Despite the recognition of the impact of more diagnostic criteria, professionals appear to depend primarily on dynamic visual cues when inferring the future performance of entrepreneurs and their businesses.

These findings draw attention to a phenomenon that has significant implications for entrepreneurs, investors, and entrepreneurship more broadly: investors seem to detect entrepreneurial passion primarily through visual information rather than through the other types of cues available during pitches. Investors detect these visual cues rapidly, and their lay theories do 


\section{VISUALS DOMINATE INVESTOR JUDGMENT}

not match how they actually make decisions. Finally, investors do not appear to pick up on relevant information better than novices, even though we might expect them to have had greater exposure to institutionalized frameworks that would aid in making such decisions. The findings confront us with the necessity of reexamining what outcomes and values are most important in entrepreneurial decision making. Privileging dynamic visual cues over other information, combined with the competitive and time-pressured constraints of pitch settings and evaluative processes, can lead to unintended outcomes that have suboptimal consequences for entrepreneurs and investors alike.

These results can be situated in the context of pivotal recent research on this topic. Although some work has noted the salience and ease of processing of visual information (Cardon et al., 2009; Chen at al., 2009), there has been a range of findings regarding whether and how visual cues - particularly through affective passion-impact judgment in the investment space. For example, although affective passion does not seem to significantly impact judgments in a VC setting (Chen et al., 2009), such nonverbal cues do seem to positively impact decisions in crowdfunding (Li, Chen, Fisher, \& Kotha, 2017).

Of particular note are Chen et al.'s (2009) findings that the lexical content of business plans appears to have a greater impact on funding decisions than entrepreneurs' affective passion. These findings can be viewed as complementary and even consistent with the current results. In Chen et al.'s work, participants were first given the business plan's written executive summary to deliberate on for a considerable amount of time (ten minutes in one study, one week in the second study); only after that process did participants see the entrepreneur's pitch presentations. Thus, the initial thin-slice impressions from Chen et al.'s studies came from the substance of the executive 


\section{VISUALS DOMINATE INVESTOR JUDGMENT}

summaries. Given that initial impressions can impact how subsequent information is processed, preparedness may indeed have dominated and continued to dominate decisions.

Consistently, this could also account for why perceived passion (affect) had a significant effect in Li et al.'s (2017) studies, as the crowdfunding communities that originally funded the projects had access to both videos and other corresponding project information at the same time. The order of information presentation (sequential versus simultaneous) might be an important contextual factor that moderates the affective passion effect on funding decisions. It would be interesting to test this premise empirically using the same materials, such as reversing the sequence and allowing entrepreneurs to pitch before judges view business propositions. In contrast, it is possible that in the type of entrepreneurship pitch competitions studied in the current work, although the original judges still had access to both the written summaries and the live presentations, such information was accessed in a more simultaneous manner, at which point visuals tend to dominate other types of information.

Several studies in this current work appear to suggest that people exclude key information from consideration when making judgments. According to the concept of change blindness (Levin \& Simons, 1997; Rensink et al., 1997; Simons \& Chabris, 1999), when we focus our attention on particular visual cues, we may not perceive other available visual cues, especially peripheral ones, because of our limited cognitive resources. The current work suggests that the original judges may have been driven primarily by the information that most people believe to be more peripheral to this domain. People's choices more accurately reflected expert judges' original outcomes when they only had access to visual cues that most people deem less substantive; when they actually had access to substantive business plans, they were unable to select the actual winners at rates above 


\section{VISUALS DOMINATE INVESTOR JUDGMENT}

chance. This finding illustrates disparities between our preferences and the visually guided choices we actually make.

Finally, throughout the studies, people were consistently more able to identify the original competition winners through visuals alone as compared to videos with sound. This may appear counterintuitive, as videos with sound offer more information and a closer approximation of the original conditions under which the decisions were made. Such findings may also seem to be not fully aligned with previous research on communication channel richness (Daft \& Lengel, 1986).

The final experiment provides initial evidence for the most likely explanation for the pattern of results in this research: conditions of cognitive load may prompt a greater reliance on visual over other types of information. Under experimental conditions that may prompt relatively less of a cognitive load than the original competition judging contexts, participants encountering videos with sound were more able to better factor in a consideration of the business proposition content. Ironically, this led to a reduced alignment with the original decisions. Facing ordinary cognitive limitations during the original competitions, the judges who had access to both visuals and sound may have depended more on visuals. Thus, the visual-only condition yielded the greatest alignment with the original judging decisions, and the videos with sound yielded improved

alignment only after cognitive load was experimentally imposed to better simulate the original overloaded conditions. One implication of these results is that we should more carefully consider processes under which we expect experts and other judges to make consequential investment decisions and structure appropriate interventions to allow for the outcomes that align with our values.

\section{Limitations and Future Research}




\section{VISUALS DOMINATE INVESTOR JUDGMENT}

One caveat to these findings is that it is difficult to determine with certainty whether the original pitch-competition judges intended to determine the winners on the basis of substantive information. Given that people are often unwilling or unable to report how they made their decisions (Greenwald \& Banaji, 1995; Schienker, Dlugolecki, \& Doherty, 1994), and given that that real-time monitoring of the processing of information may disrupt decision processes and pose issues for external validity, the current studies used real competition footage and outcomes to extrapolate the basis of investor decisions. Accordingly, the current work focused on the inference that the original judges appear to have relied predominantly on visual cues when choosing winners. Identifying the winners of pitch competitions was one method used to infer judges' decisionmaking processes; this choice did not carry an evaluative statement that the winners are necessarily the "best" entrepreneurial projects.

The question of whether investor decisions ultimately are revealed to be more or less profitable is interesting but beyond the scope of the current studies. Future work can investigate the relevance of judgments to later and long-term outcomes. The current results suggest that evaluators may not be fully aware of the basis of their judgments and hence might be introducing error into their decisions, relative to what they value. However, such misalignment between stated beliefs and actual processes may not necessarily entail bias. It is possible that visual cues contain valid information and that being influenced by passion in a setting with complex and ambiguous information leads to better choices, even if the inaccurate attribution remains. By following the long-term outcomes of startups associated with the winning and non-winning pitches, we would be in a better position to discuss when visual dependence introduces error into decisions. We would also be better able to assess whether perceived passion is a good predictor of future performance. 


\section{VISUALS DOMINATE INVESTOR JUDGMENT}

In addition, the conclusions may be tempered, in that although the results consistently point to dominance of visual information in decision making, investments are often based on a series of progressively longer presentations, coupled with weeks of due diligence and negotiations. It is possible that, with more information, the impact of visuals may be modulated; however, in the context of the earlier discussion regarding the possible influence of the sequencing of information, it may be that as long as visuals are available alongside other information from the outset of evaluations, they can continue to be more influential.

One explanation for the dominance of visuals in investor judgment hinges on the fact that in the seconds before a pitch begins, as the entrepreneur enters the stage, only visual information is available. If those initial seconds of information heavily impacted investors' judgments of the rest of the presentation, this could also account for how the visuals alone were more predictive of the final outcomes. This possibility could be tested in future research. Similarly, it would be interesting to investigate whether implicit primes or explicit instructions could shift this dependence on visual information.

A further follow-up question might investigate whether there is more variance in decisions made through auditory content only versus visuals, beyond the overall patterns pointing to the dominance of visuals. Previous work suggests that the level of variance in evaluation across conditions may be similar; the degree of variance perceived through sound is similar to the degree of variance perceived through visuals, even in the domain of music (Tsay, 2013).

Turning to the underlying mechanisms, passion emerged as the most significant predictor of winning entrepreneurship pitch competitions, similar to its contribution to the premium on visual cues in other domains (Tsay, 2013). However, the impact of secondary other factors on 


\section{VISUALS DOMINATE INVESTOR JUDGMENT}

judgment appears to be more context and domain dependent. For example, confidence may be recognized as more important for and predictive of future success in entrepreneurship, whereas uniqueness may be privileged to a greater degree in the arts. Surveys of attitudes about idealized representatives across domains may guide us toward a better understanding of the types of factors best associated with success in those fields.

It would also be important to explore whether selecting candidates based on passion rather than other valued qualities may in fact be justified in entrepreneurship. Passion, motivation, and effort are important to entrepreneurs' long-term success (Fried \& Hisrich, 1994; Latham \& Pinder, 2005; Locke \& Latham, 2002; Staw \& Barsade, 1993; Tyebjee \& Bruno, 1984), and these qualities may have been reflected through visual information in my study. However, the substantive content of business plans should have had some impact, if not a dominant one, on competition outcomes. It is possible that entrepreneurs are more motivated by the understanding that business plans are likely to change, whereas passion is perceived as a more trait-like, difficult-to-cultivate quality that aligns more with intuition or with the concept of natural talent (Tsay, 2016). Investors may have good reason to bet on people more than on business plans.

Future work might also explore how different aspects of passion contribute to expert judgment. Although the current design likely prompted the application of lay theories about passion, such as strong emotion and enthusiasm (Cardon et al., 2005), it does not allow participants to disentangle different facets of passion, such as displayed affective passion, cognitive passion, and behavioral passion (Cardon et al., 2009).

The current set of studies focused primarily on winning entrepreneurs - those who receive funding and win backing from investors - with visible passion appearing to contribute to these 


\section{VISUALS DOMINATE INVESTOR JUDGMENT}

decisions. Another area of future research could investigate whether this effect is moderated by the valence of visuals. That is, in the current focus on top performers, most visuals likely conveyed something positive (i.e., passion). But what if the visuals portrayed candidates who fell to the other end of the spectrum? Would the reverse effect emerge, such that visuals lead the candidate to be evaluated worse than in the absence of visuals? It would also be interesting to test whether the gender or ethnicity of the entrepreneurs might moderate the effect; would investors be more likely to depend on visible passion when evaluating a competition in which the finalists all happen to be entrepreneurs who have been historically underrepresented?

Although the current work focused on the impact of dynamic visual information, and thus included only pitch competitions where slides were not used, many competitions do include the use of slide decks. Future work might test the relative influence of this type of visual information. For example, beyond the dynamic visual information that entrepreneurs may display, how might the visual design and richness of their slides affect judges' decisions, relative to the content portrayed in the slides or revealed aurally in the pitch? How might such different types of materials, such as slides or displays of actual products, affect investor engagement?

More broadly, what are the main differences between the video-with-sound condition in which people can see and hear everything versus situations in which the actual competitions were held? Although even the original judging panels would be unlikely to reach full consensus about the winners (Fehder \& Murray, 2018; Howell, 2020; Tsay, 2013), and often rankings or scores may be averaged across judges (Howell, 2020), there may be other aspects in live competitions that are not well-captured by the videos with sound, including spontaneous audience or peer responses that may have influenced the original judges. 


\section{VISUALS DOMINATE INVESTOR JUDGMENT}

The current findings suggest people depend greatly on visual information when making decisions and thus may also be more discriminating in using visual information, being more used to parsing visual cues for answers. It is possible that those who have not undergone this process may process information quite differently. For example, would congenitally blind people who rely more on other senses be more discriminating when judging based on auditory information alone? If so, would this suggest that with respect to judgments that we believe should depend on more substantive information, we are in effect blinded by our sight?

Finally, this line of work could be extended to examine what engages people with others and their ideas. The research on social tuning suggests that the belief that others are experiencing the same stimuli makes those stimuli more psychologically meaningful (Shteynberg, 2010). Visual cues could be particularly important to thinking that others are experiencing the same stimuli. People many not only weight visual information more, but also may find it to be more psychologically meaningful, such that they consider the content of an entrepreneur's pitch more deeply when they have first been engaged by visual cues.

In addition to contributing to any context that involves the professional evaluation of performance quality, this research also holds implications for other organizational outcomes, such as leadership, interpersonal influence, and communication. Although visual information can be reliable and adaptive in some contexts, we value content and rationality in our decision making. Yet, without our awareness, we use visual information implicitly and automatically to make inferences about quality and content. Future work may explore ways to attenuate any costs of this visual dominance and ensure greater consistency between what we value and evaluate. 


\section{VISUALS DOMINATE INVESTOR JUDGMENT}

\section{REFERENCES}

Amabile, N., Krabbenhoft, M. A., \& Hogan, D. 2006. The 30-second sale: Using thin slice judgments to evaluate sales effectiveness. Journal of Consumer Psychology, 16: 4-13.

Amabile, T. \& Kabat, L. 1982. When self-descriptions contradict behavior: Actions do speak louder than words. Social Cognition, 1: 311-335.

Ambady, N., \& Rosenthal, R. 1993. Half a minute: Predicting teacher evaluations from thin slices of nonverbal behavior and physical attractiveness. Journal of Personality and Social Psychology, 64(3): 431.

Anderson, C., \& Kilduff, G. 2009. Why do dominant personalities attain influence in face-to-face groups? The competence-signaling effects of trait dominance. Journal of Personality and Social Psychology, 96: 491-503.

Arvey, R. \& Campion, J. 1982. The employment interview: A summary and review of recent research. Personnel Psychology, 35: 281-314.

Baron, R. 2008. The role of affect in the entrepreneurial process. Academy of Management Review, 33(2): 328-340.

Baum, J. \& Locke, E. 2004. The relationship of entrepreneurial traits, skill, and motivation to subsequent venture growth. Journal of Applied Psychology, 89(4): 587-598.

Beehr, T. A. \& Gilmore, D. C. 1982. Applicant attractiveness as a perceived job relevant variable in selection. Academy of Management Journal, 25: 607-617.

Bhide A. (2000). The origin and evolution of new ventures. New York: Oxford University Press. 


\section{VISUALS DOMINATE INVESTOR JUDGMENT}

Biddle, J. \& Hamermesh, D. 1998. Beauty, productivity, and discrimination: Lawyers' looks and lucre. Journal of Labor Economics, 16(1): 172-201.

Bierly, P., Kessler, E., \& Christensen, E. 2000. Organizational learning, knowledge and wisdom. Journal of Organizational Change Management, 13(6): 595-618.

Bird, B.J. 1989. Entrepreneurial behavior. Glenview, IL: Scott Foresman.

Boekaerts, M. 2017. Cognitive load and self-regulation: Attempts to build a bridge. Learning and Instruction, 51: 90-97.

Braun, C. C., \& Silver, N. C. 1995. Interaction of signal word and colour on warning labels: Differences in perceived hazard and behavioral compliance. Ergonomics, 38: 2207-2220.

Brooks, A.W., Huang, L., Kearney, S.W., \& Murray, F. 2014. Investors prefer entrepreneurial ventures pitched by attractive men. Proceedings of the National Academy of Sciences of the United States of America, 111(12): 4427-4431.

Buhrmester, M., Kwang, T., \& Gosling, S. D. 2011. Amazon's Mechanical Turk: A new source of inexpensive, yet high-quality, data? Perspectives on Psychological Science, 6(1): 3-5.

Cardon, M.S. 2008. Is passion contagious? The transference of entrepreneurial emotion to employees, Human Resource Management Review, 18 (2): 77-86.

Cardon, M. S., Gregoire, D. A., Stevens, C. E., \& Patel, P. C. 2013. Measuring entrepreneurial passion: Conceptual foundations and scale validation. Journal of Business Venturing, 28(3): 373-396.

Cardon, M., Wincent, J., Singh, J., Drnovsek, M. 2009. The nature and experience for entrepreneurial passion. Academy of Management Review 34(3): 511-532. 


\section{VISUALS DOMINATE INVESTOR JUDGMENT}

Carter, R. B. \& Van Auken, H. 1992 effect of professional background on venture capital proposal evaluation. Journal of Small Business Strategy, 3(1): 45-55.

Chan, C. S. R., \& Park, H. D. 2015. How images and color of business plans influence venture investment screening decisions. Journal of Business Venturing, 30: 732-748.

Chen, X., Yao, X., \& Kotha, S. 2009. Entrepreneur passion and preparedness in business plan presentations: A persuasion analysis of venture capitalists' funding decision. Academy of Management Journal, 52(1): 199-214.

Clarke, J. S., Cornelissen, J. P., \& Healey, M. P. 2019. Actions speak louder than words: How figurative language and gesturing in entrepreneurial pitches influences investment judgments. Academy of Management Journal, 62(2): 335-360.

Cook, T. D., \& Campbell, D. T. 1979. Quasi-experimentation: Design and analysis issues for field settings. Boston, MA: Houghton Mifflin Company.

Daft, R. L., \& Lengel, R. H. 1986. Organizational information requirements, media richness and structural design. Management Science, 32(5): 554-571.

DePaulo, B. M., Lassiter, G., \& Stone, J. I. 1982. Attentional determinants of success at detecting deception and truth. Personality and Social Psychology Bulletin, 8(2): 273-279.

Dion, K. K., Berscheid, E., \& Walster, E. 1972. What is beautiful is what is good. Journal of Personality and Social Psychology, 24: 285-290.

Dovidio, J. F., Evans, N. E., \& Tyler, R. B. 1986. Racial stereotypes: The contents of their cognitive representations. Journal of Experimental Social Psychology, 22: 22-37.

Elsbach, K. D. \& Kramer, R. M. 2003. Assessing creativity in Hollywood pitch meetings: Evidence for a dual-process model of creativity judgments. Academy of Management 


\section{VISUALS DOMINATE INVESTOR JUDGMENT}

Journal, 46: 283-301.

Fehder, D., \& Murray, F. 2018. Evaluation of early-stage ventures: Bias across different evaluation regimes. Academy of Management Proceedings, 1: 17519.

Frith, S. 1998. Performing rites: On the value of popular music. Cambridge: Harvard University Press.

Gaertner, S. L., \& McLaughlin, J. P. 1983. Racial stereotypes: Associations and ascriptions of positive and negative characteristics. Social Psychology Quarterly, 46: 23-30.

Gartner, W. 1990. What are we talking about when we talk about entrepreneurship? Journal of Business Venturing, 5(1): 15-28.

Gilbert, D., \& Hixon, J. 1991. The trouble of thinking: Activation and application of stereotypic beliefs. Journal of Personality and Social Psychology, 60(4): 509-517.

Goldin, C. \& Rouse, C. 2000. Orchestrating impartiality: The impact of "blind" auditions on female musicians. American Economic Review, 90: 715-741.

Greenwald, A. G., \& Banaji, M. R. 1995. Implicit social cognition: attitudes, self-esteem, and stereotypes. Psychological Review, 102(1): 4-27.

Harrigan, J. A., Wilson, K., \& Rosenthal, R. 2004. Detecting state and trait anxiety from auditory and visual cues: A meta-analysis. Personality and Social Psychology Bulletin, 30(1): 5666.

Hayward, M., Forster, W., Sarasvathy, S. and Frederickson, B. 2010. Beyond hubris: How highly confident entrepreneurs rebound to venture again. Journal of Business Venturing, 25 6: $569-578$. 


\section{VISUALS DOMINATE INVESTOR JUDGMENT}

Hochschild, A. 1983. The managed heart: Commercialization of human feeling. Berkeley: University of California Press.

Howell, S. 2020. Reducing information frictions in venture capital: The role of new venture competitions. The Journal of Financial Economics, 136 (3): 676-694.

Huffcutt, A. I. 2011. An empirical review of the employment interview construct literature. International Journal of Selection and Assessment, 19: 62-81.

Jack, R. E., Sun, W., Delis, I., Garrod, O. G. B. and Schyns, P. G. 2016. Four not six: revealing culturally common facial expressions of emotion. Journal of Experimental Psychology: General, 145(6): 708-730.

Kahneman, D., \& Tversky, A. 1996. On the reality of cognitive illusions: A reply to Gigerenzer's critique. Psychological Review, 103: 582-591.

Kaplan, S., \& Stromberg, P. 2003. Financial contracting theory meets the real world: An empirical analysis of venture capital contracts. Review of Economic Studies, 70(2): 281-315.

Kelley, T. 2001. The art of innovation: Lessons in the creativity from IDEO, America's leading design firm. New York: Doubleday.

Kittur, A., Chi, E. H., \& Suh, B. 2008. Crowdsourcing user studies with Mechanical Turk. Paper presented at the Proceedings of the SIGCHI conference on human factors in computing systems.

Krauss, R., Freyberg, R., \& Morsella, E. 2002. Inferring speakers' physical attributes from their voices. Journal of Experimental Social Psychology, 38(6): 618-625.

Krishna, A., \& Schwarz, N. 2014. Sensory marketing, embodiment, and grounded cognition: A review and introduction. Journal of Consumer Psychology, 24(2): 159-68. 


\section{VISUALS DOMINATE INVESTOR JUDGMENT}

Latham, G. P., \& Pinder, C. C. 2005. Work motivation theory and research at the dawn of the twenty-first century. Annual Review of Psychology, 56: 485-516.

Levin, D. \& Simons, D. 1997. Failure to detect changes to attended objects in motion pictures, Psychonomic Bulletin and Review, 4(4): 501-506.

Li, J. J., Chen, X.-P., Kotha, S., \& Fisher, G. 2017. Catching fire and spreading it: A glimpse into displayed entrepreneurial passion in crowdfunding campaigns. Journal of Applied Psychology, 102(7): 1075-1090.

Locke, E. A., \& Latham, G. P. 1990. A theory of goal setting and task performance. Englewood Cliffs, NJ: Prentice Hall.

Locke, E. A., \& Latham, G. P. 2002. Building a practically useful theory of goal setting and task motivation: A 35-year odyssey. American Psychologist, 57: 705-717.

Macmillan, I. \& Narasimha, P. 1987. Research notes and communications: Characteristics distinguishing funded from unfunded business plans evaluated by venture capitalists. Strategic Management Journal, 8: 579-585.

Maranges, H. M., Schmeichel, B. J., \& Baumeister, R. F. 2017. Comparing cognitive load and self-regulatory depletion: Effects on emotions and cognitions. Learning and Instruction, 51: 74-84.

Maxwell, A. L., \& Lévesque, M. 2014. Trustworthiness: A critical ingredient for entrepreneurs seeking investors. Entrepreneurship Theory and Practice, 38(5): 1057-1080.

Mehta, R., \& Zhu, R. J. 2009. Blue or red? Exploring the effect of color on cognitive task performances. Science, 323: 1226-1229. 


\section{VISUALS DOMINATE INVESTOR JUDGMENT}

Mitteness, C., Baucus, M., \& Sudek, R. 2012. Horse vs. Jockey? How stage of funding process and industry experience affect the evaluations of angel investors. Venture Capital, 14(4): 241267.

Mitteness, C., Sudek, R., \& Cardon, M. S. 2012. Angel investor characteristics that determine whether perceived passion leads to higher evaluations of funding potential. Journal of Business Venturing, 27: 592-606.

Na, J., Kim, S., Oh, H., Choi, I., \& O’Toole, A. 2015. Competence judgments based on facial appearance are better predictors of American elections than of Korean elections. Psychological Science, 26(7): 1107-1113.

Navis, C., \& Glynn, M. 2011. Legitimate distinctiveness and the entrepreneurial identity: Influence on investor judgments of new venture plausibility. Academy of Management Review, 36(3): 479-499.

Paolacci, G., Chandler, J., \& Ipeirotis, P. 2010. Running experiments on Amazon Mechanical Turk. Judgment and Decision Making, 5(5): 411-419.

Payne, W. H. and Macarty, M. J. 2002. The anatomy of an angel investing network: Tech coast angels. Venture Capital, 4: 331-336.

Pentland, A. 2010. We can measure the power of charisma. Harvard Business Review, 88(1): 3435.

Petty, J. \& Gruber, M. 2011. In pursuit of the real deal: A longitudinal study of VC decision making. Journal of Business Venturing, 26(2): 172-188.

Rasmussen, K. 1984. Nonverbal behavior, verbal behavior, resumé credentials, and selection interview outcomes. Journal of Applied Psychology, 69(4): 551-556. 


\section{VISUALS DOMINATE INVESTOR JUDGMENT}

Rasmussen, R. \& Sorheim, R. 2012. Obtaining early-stage financing for technology entrepreneurship: Reassessing the demand-side perspective. Venture Capital, 14(2-3): 7789.

Rensink, R., O'Regan, J., \& Clark, J. 1997. To see or not to see: the need for attention to perceive changes in scenes. Psychological Science, 8(5): 368-373.

Robbie, W., \& Mike, K. 1998. Venture capital and private equity: A review and synthesis. Journal of Business Finance \& Accounting, 25(5-6): 521-570.

Sager, H. A., \& Schofield, J. W. 1980. Racial and behavioral cues in black and white children's perceptions of ambiguously aggressive acts. Journal of Personality and Social Psychology, 39: 590-598.

Schlenker, B. R., Dlugolecki, D. W., \& Doherty, K. 1994. The impact of self-presentations on selfappraisals and behavior: The power of public commitment. Personality and Social Psychology Bulletin, 20(1): 20-33.

Shane, S. 2000. A general theory of entrepreneurship: The individual-opportunity nexus. Northampton: Edward Elgar Publishing.

Shane, S., Locke, E. A., \& Collins, C. J. 2012. Entrepreneurial motivation. Human Resource Management Review, 13(2): 257-279.

Shepherd, D. A. 1999. Venture capitalists' assessment of new venture survival. Management Science, 45(5): 621-633.

Shteynberg, Garriy. 2010. A silent emergence of culture: The social tuning effect. Journal of Personality and Social Psychology, 99(4): 683 


\section{VISUALS DOMINATE INVESTOR JUDGMENT}

Simons, D.J. \& Chabris, C.F. 1999. Gorillas in our midst: Sustained inattentional blindness for dynamic events. Perception, 28(9): 1059-1074.

Simmons, J. P., Nelson, L. D., \& Simonsohn, U. 2011. False-positive psychology: Undisclosed flexibility in data collection and analysis allows presenting anything as significant. Psychological Science, 22(11): 1359-1366.

Smilor, R. 1997. Entrepreneurship: Reflections on a subversive activity. Journal of Business Venturing, 12: 341-346.

Smith, E. R. 1984. Model of social inference processes. Psychological Review, 91: 392-413.

Sorokin, A., \& Forsyth, D. 2008. Utility data annotation with Amazon Mechanical Turk. Paper presented at the Computer Vision and Pattern Recognition Workshops, IEEE Computer Society Conference.

Staw, B. M., \& Barsade, S. G. 1993. Affect and managerial performance. A test of the sadder-butwiser vs. happier-and-smarter hypotheses. Administrative Science Quarterly, 38: 304333.

Stevens, C. \& Kristoff, A. 1995. Making the right impression: A field study of impression management during job interviews. Journal of Applied Psychology, 80: 587-606.

Tanaka, A., Koizumi, A., Imai, H., Hiramatsu, S., Hiramoto, E., \& de Gelder, B. 2010. I feel your voice: Cultural differences in the multisensory perception of emotion. Psychological Science, 21(9): 1259-1262.

Tsay, C. 2013. Sight over sound in the judgment of music performance. Proceedings of the National Academy of Sciences, 110(36): 14580-14585. 


\section{VISUALS DOMINATE INVESTOR JUDGMENT}

Tsay, C. 2014. The vision heuristic: Judging music ensembles by sight alone. Organizational Behavior and Human Decision Processes, 124(1): 24-33.

Tsay, C. 2016. Privileging naturals over strivers: The costs of the naturalness bias. Personality and Social Psychology Bulletin, 42(1): 40-53.

Tyebjee, T. T. \& Bruno, A. V. 1984. A model of venture capitalist investment activity. Management Science, 30(9): 305-322.

Vallerand, R.J., Blanchard, C. M., Mageau, G.A., Koestner, R., Ratelle, C., Léonard, M., Gagné, M., \& Marsolais, J. 2003. Les passions de l'âme: On obsessive and harmonious passion. Journal of Personality and Social Psychology, 85: 756-767.

van Werven, R., Bouwmeester, O., \& Cornelissen, J. P. 2019. Pitching a business idea to investors: How new venture founders use micro-level rhetoric to achieve narrative plausibility and resonance. International Small Business Journal, 37(3): 193-214.

Wiltbank, R., Read, S., Dew, N., \& Sarasvathy, S. D. 2009. Prediction and control under uncertainty: Outcomes in angel investing. Journal of Business Venturing, 24(2): 116133.

Zott, C., \& Huy, Q. N. 2007. How entrepreneurs use symbolic management to acquire resources. Administrative Science Quarterly, 52(1): 70-105. 


\section{VISUALS DOMINATE INVESTOR JUDGMENT}

\section{TABLE 1. Summary of experiments.}

$\mathrm{V}=$ Visual only, $\mathrm{A}=$ Sound only, $\mathrm{V}+\mathrm{A}=$ Video with Sound, $\mathrm{T}=$ Transcript.

\begin{tabular}{|c|c|c|c|c|c|}
\hline Exp. & $\mathbf{N}$ & $\begin{array}{l}\text { Participant } \\
\text { Type }\end{array}$ & $\begin{array}{l}\text { Stimuli Type } \\
\text { and Main DV }\end{array}$ & $\begin{array}{c}\text { Versus at Chance (33\%) } \\
\text { (one sample t-tests) }\end{array}$ & $\begin{array}{c}\text { Against } \\
\text { Other Conditions } \\
\text { (independent-samples t-tests) }\end{array}$ \\
\hline 1 & 501 & $\begin{array}{l}\text { General } \\
\text { community } \\
\text { sample }\end{array}$ & $\begin{array}{l}\text { Short pitch } \\
\text { excerpts } \\
\text { (3 versions); } \\
\text { Prediction of } \\
\text { original winner }\end{array}$ & $\begin{array}{l}\text { V: } 52.2 \%, t(171)=11.82, \\
P<0.001 \\
\text { A: } 35.6 \%, t(159)=1.72 \\
P=\text { n.s. } \\
\text { V+A: } 43.6 \%, t(168)= \\
6.73, P<0.001\end{array}$ & $\begin{array}{l}\text { V vs. A: } \\
t(330)=7.96, P<0.001 \\
\text { V vs. V+A: } \\
t(339)=3.91, P<0.001 \\
\text { A vs. V+A: } \\
t(327)=-3.95, P<0.001\end{array}$ \\
\hline 2 & 117 & $\begin{array}{l}\text { General } \\
\text { online } \\
\text { sample }\end{array}$ & $\begin{array}{l}\text { Short pitch } \\
\text { excerpts } \\
\text { (3 versions); } \\
\text { Participant } \\
\text { choice of winner }\end{array}$ & $\begin{array}{l}\text { V: } 45.0 \%, t(36)=3.23, \\
P=0.003 \\
\text { A: } 32.4 \%, t(35)=-0.40, \\
P=\text { n.s. } \\
\text { V+A: } 39.1 \%, t(43)=2.22, \\
P=0.032\end{array}$ & $\begin{array}{l}\text { V vs. A: } \\
t(71)=2.92, P=0.005 \\
\text { V vs. V+A: } \\
t(79)=1.35, P=\text { n.s. } \\
\text { A vs. } \mathrm{V}+\mathrm{A}: \\
t(78)=-1.89, P=\text { n.s. }\end{array}$ \\
\hline 3 & 164 & $\begin{array}{l}\text { General } \\
\text { community } \\
\text { sample }\end{array}$ & $\begin{array}{l}\text { Pitch excerpts } \\
\text { (2 versions); } \\
\text { Prediction of } \\
\text { original winner }\end{array}$ & $\begin{array}{l}\text { V: } 42.34 \%, t(45)=3.02, \\
P=0.004 \\
\text { T: } 32.7 \%, t(118)=-0.45, \\
P=\text { n.s. }\end{array}$ & $\begin{array}{l}\text { V vs. T: } \\
t(163)=3.33, P=0.001\end{array}$ \\
\hline 4 & 93 & $\begin{array}{l}\text { General } \\
\text { online } \\
\text { sample }\end{array}$ & $\begin{array}{l}\text { Full pitch } \\
\text { excerpts } \\
\text { (3 versions); } \\
\text { Prediction of } \\
\text { original winner }\end{array}$ & $\begin{array}{l}\text { V: } 50.6 \%, t(33)=5.16, \\
P<0.001 \\
\text { A: } 40.2 \%, t(28)=2.31, \\
P=0.029 \\
\text { V+A: } 46.8 \%, t(32)=4.26, \\
P<0.001\end{array}$ & $\begin{array}{l}\text { V vs. A: } \\
t(61)=2.28, P=0.026 \\
\text { V vs. } \mathrm{V}+\mathrm{A}: \\
t(65)=0.83, P=\text { n.s. } \\
\text { A vs. } \mathrm{V}+\mathrm{A}: \\
t(60)=-1.50, P=\text { n.s. }\end{array}$ \\
\hline $5 a$ & 150 & $\begin{array}{l}\text { Experienced } \\
\text { entrepreneurs }\end{array}$ & $\begin{array}{c}\text { Full pitch } \\
\text { excerpts } \\
\text { (3 versions); } \\
\text { Participant } \\
\text { choice of winner }\end{array}$ & $\begin{array}{l}\text { V: } 42.2 \%, t(54)=3.70, \\
P=0.001 \\
\text { A: } 33.3 \%, t(44)=0.00, \\
P=\text { n.s } \\
\text { V+A: } 41.6 \%, t(50)=3.23, \\
P=0.002\end{array}$ & $\begin{array}{l}\text { V vs. A: } \\
t(97)=2.63, P=0.010 \\
\text { V vs. V+A: } \\
t(104)=0.17, P=\text { n.s. } \\
\text { A vs. V+A: } \\
t(93)=-2.38, P=0.019\end{array}$ \\
\hline $5 b$ & 187 & $\begin{array}{l}\text { Experienced } \\
\text { investors }\end{array}$ & $\begin{array}{l}\text { Short pitch } \\
\text { excerpts } \\
\text { (3 versions); }\end{array}$ & $\begin{array}{l}\mathrm{V}: 43.8 \%, t(66)=4.92 \\
P<0.001 \\
\mathrm{~A}: 27.7 \%, t(54)=-3.28 \\
P=0.002\end{array}$ & $\begin{array}{l}\text { V vs. A: } \\
t(120)=5.71, P<0.001 \\
\text { V vs. V+A: } \\
t(130)=2.48, P=0.015 \\
\text { A vs. } \mathrm{V}+\mathrm{A}:\end{array}$ \\
\hline
\end{tabular}




\section{VISUALS DOMINATE INVESTOR JUDGMENT}

\begin{tabular}{|c|c|c|c|c|c|}
\hline & & & $\begin{array}{c}\text { Participant } \\
\text { choice of winner }\end{array}$ & $\begin{array}{l}\text { V+A: } 36.2 \%, t(64)=1.33 \\
P=\text { n.s. }\end{array}$ & $t(118)=-3.00, P=0.003$ \\
\hline $6 a$ & 34 & $\begin{array}{c}\text { General } \\
\text { community } \\
\text { sample }\end{array}$ & $\begin{array}{c}\text { Short pitch } \\
\text { excerpts } \\
\text { (Video only); } \\
\text { Possible } \\
\text { mechanisms: } \\
\text { confidence, } \\
\text { physical } \\
\text { attractiveness, } \\
\text { passion, } \\
\text { uniqueness }\end{array}$ & $\begin{array}{l}\mathrm{V}_{\text {Conf: }} 48.4 \%, t(40)=4.05, \\
P<0.001 \\
\mathrm{~V}_{\text {Phys: }} 34.4 \%, t(40)=0.38, \\
P=\mathrm{n} . \mathrm{s} \\
\mathrm{V}_{\text {Pass: }} 58.8 \%, t(40)=6.56 \\
P<0.001 \\
\mathrm{~V}_{\text {Uni: }} 35.3 \%, t(40)=0.54 \\
P=\text { n.s }\end{array}$ & N/A \\
\hline $6 b$ & 196 & $\begin{array}{l}\text { General } \\
\text { online } \\
\text { sample }\end{array}$ & $\begin{array}{l}\text { Short pitch } \\
\text { excerpts } \\
\text { (2 versions); } \\
\text { Perceived } \\
\text { passion }\end{array}$ & $\begin{array}{l}\mathrm{V}: 60.2 \%, t(98)=15.01 \\
P<0.001 \\
\text { A: } 33.4 \%, t(96)=0.08 \\
P=\text { n.s }\end{array}$ & $\begin{array}{l}\text { V vs. A: } \\
t(194)=11.67, P<0.001\end{array}$ \\
\hline $6 c$ & 52 & $\begin{array}{l}\text { General } \\
\text { online } \\
\text { sample }\end{array}$ & $\begin{array}{l}\text { Short pitch } \\
\text { excerpts } \\
\text { (Video only); } \\
\text { Perceived } \\
\text { passion, } \\
\text { 5-point scale }\end{array}$ & $\begin{array}{l}M_{\text {Winner }}=2.38, \\
S D_{\text {Winner }}=0.58 ; \\
M_{\text {Non-Winner }}=1.66, \\
S D_{\text {Non-Winner }}=0.61\end{array}$ & $t(51)=18.07, P<0.001$ \\
\hline $\mathrm{S} 1$ & 36 & $\begin{array}{l}\text { General } \\
\text { online } \\
\text { sample }\end{array}$ & $\begin{array}{l}\text { Photographs of } \\
\text { entrepreneurs; } \\
\text { Prediction of } \\
\text { original winner }\end{array}$ & $\begin{array}{l}\text { P: } 37.5 \%, t(35)=1.53, \\
P=\text { n.s }\end{array}$ & N/A \\
\hline 7 & 148 & $\begin{array}{l}\text { General } \\
\text { online } \\
\text { sample }\end{array}$ & $\begin{array}{c}\text { Full pitch } \\
\text { excerpts } \\
\text { (3 versions); } \\
\text { Second set of } \\
\text { stimuli } \\
\text { Participant } \\
\text { choice of winner }\end{array}$ & $\begin{array}{l}\mathrm{V}: 47.9 \%, t(60)=8.45 \\
P<0.001 \\
\mathrm{~A}: 36.1 \%, t(40)=1.18 \\
P=\mathrm{n} . \mathrm{s} \\
\mathrm{V}+\mathrm{A}: 40.4 \%, t(45)=2.59 \\
P=0.013\end{array}$ & $\begin{array}{l}\text { V vs. A: } \\
t(100)=4.14, P<0.001 \\
\text { V vs. V+A: } \\
t(105)=2.40, P=0.018 \\
\text { A vs. V+A: } \\
t(85)=-1.19, P=\text { n.s. }\end{array}$ \\
\hline
\end{tabular}


VISUALS DOMINATE INVESTOR JUDGMENT

\begin{tabular}{|c|c|c|c|c|c|}
\hline 8 & 177 & $\begin{array}{c}\text { General } \\
\text { online } \\
\text { sample }\end{array}$ & $\begin{array}{c}\text { Full pitch } \\
\text { excerpts } \\
\text { (3 versions; test } \\
\text { of cognitive } \\
\text { load); Second set } \\
\text { of stimuli } \\
\text { Participant } \\
\text { choice of winner }\end{array}$ & $\begin{array}{l}\mathrm{V}: 48.8 \%, t(67)=7.27, \\
P<0.001 \\
\mathrm{~V}+\mathrm{A}: 41.7 \%, t(64)=4.74, \\
P<0.001 \\
\mathrm{~V}+\mathrm{A}_{\text {cogload: }} 47.3 \%, t(43)= \\
6.67, P<0.001\end{array}$ & $\begin{array}{l}\text { V vs. V+A: } \\
t(131)=2.57, P=0.011 \\
\text { V vs. V+Acogload: } \\
t(110)=0.49, P=\text { n.s. } \\
\text { V+A vs. V+A cogload: } \\
t(107)=-2.03, P=0.045\end{array}$ \\
\hline
\end{tabular}

The main experiments included t-tests because analyses were conducted on average identification rates $(\%)$ across trials per participant. 


\section{VISUALS DOMINATE INVESTOR JUDGMENT}

\section{FIGURE 1}

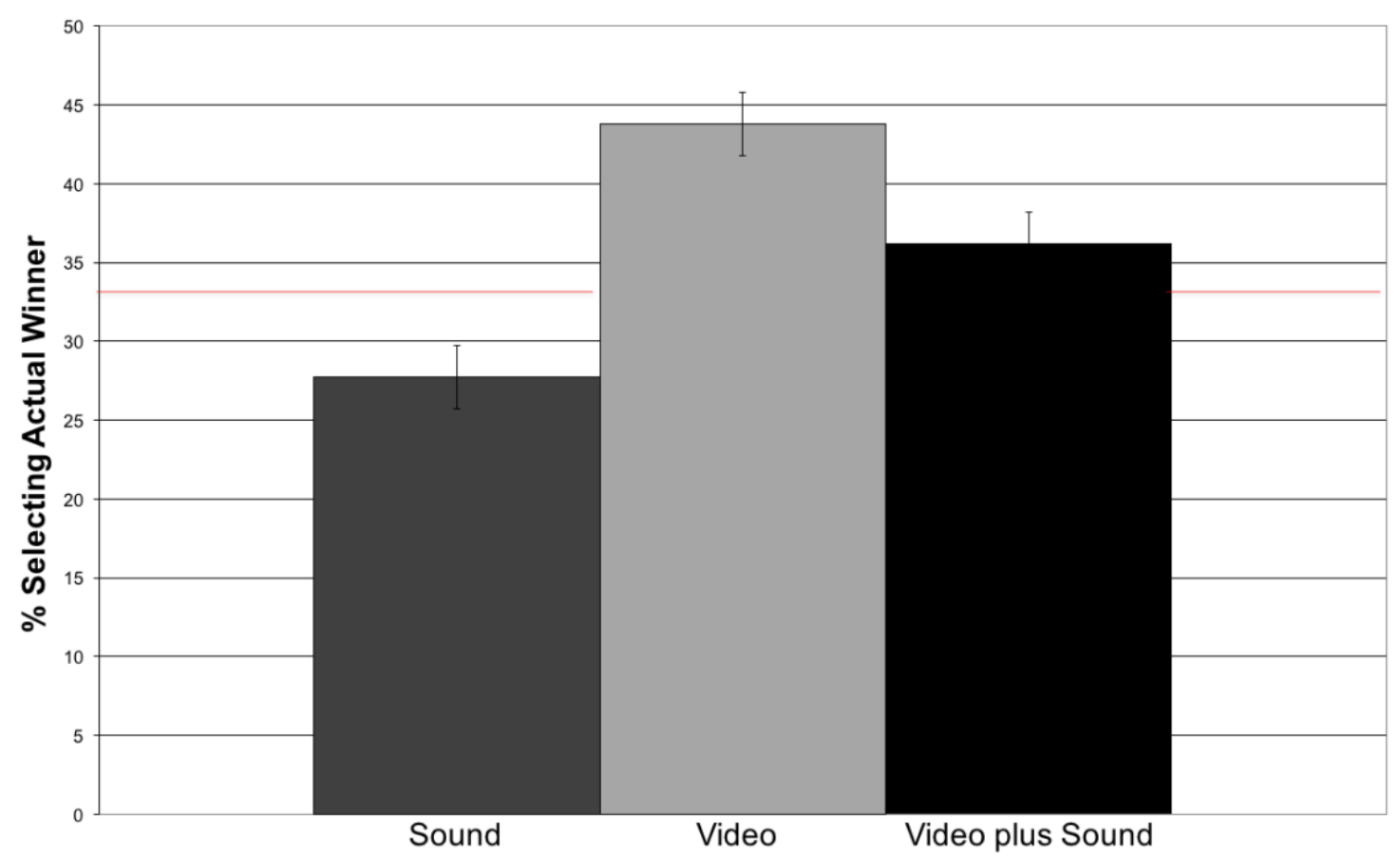

The percentage identifying actual outcomes given sound-only, video-only, or video-plus-sound recordings in Study 5b. 33 percent indicates identification performance at chance. With video-only recordings, investors performed significantly better than chance at identifying the actual winners, $t(66)=4.92, p<.001$, while they were below chance with sound-only recordings, $t(54)=-3.28, p$ $=.002$. Experts were significantly better with silent videos (43.8\%) than sound-only recordings $(27.7 \%), t(120)=5.71, p<.001$. When provided with recordings with both video and sound, investors again performed at chance at $36.2 \%, t(64)=1.33, p=n$.s. They were significantly better than those who received sound-only recordings, $t(118)=3.00, p=.003$. Those who received silent videos, when compared to those who received both video and sound, were significantly more likely to approach the actual outcomes, $t(130)=2.48, p=.015$. 


\section{BIOGRAPHY}

Chia-Jung Tsay (c.tsay@ucl.ac.uk) is an Associate Professor of Organizational Behavior at UCL School of Management, University College London. She received her Ph.D. from Harvard Business School. Her research examines the psychological processes that influence decision making and interpersonal perception. She investigates the role of expertise and nonconscious biases in professional selection and advancement.

\section{ACKNOWLEDGEMENTS}

I thank the editors and two anonymous reviewers, and Teresa Amabile, Max Bazerman, Jim Berry, Sreedhari Desai, Boris Groysberg, Laura Huang, Katie Shonk, Bart Vanneste, the INSEAD Doriot Entrepreneurship Conference, and the UCL SOM reading group for comments and feedback on earlier versions of this manuscript. Many thanks also to Nick Bakewell, Jo Burr, Paige Kemp, Zillur Rahman, and Evan Rosenman for their RA help. 